Acta Crystallographica Section D

Biological Crystallography

ISSN 1399-0047

\author{
Andrew R. Denninger, ${ }^{a}$ Bruno \\ Demé, ${ }^{\mathbf{b}}$ Viviana Cristiglio, \\ Géraldine LeDuc, ${ }^{c}$ W. Bruce \\ Feller $^{\mathrm{d}}$ and Daniel A. Kirschner ${ }^{\mathrm{a} *}$
}

${ }^{a}$ Biology Department, Boston College, Chestnut Hill, MA 02467, USA, ' Institut Laue-Langevin (ILL), CS 20156, F-38042 Grenoble CEDEX 9, France, 'European Synchrotron Radiation Facility (ESRF), CS 40220, F-38043 Grenoble CEDEX 9, France, and NOVA Scientific Inc. Sturbridge, MA 01566, USA

Correspondence e-mail: kirschnd@bc.edu

\title{
Neutron scattering from myelin revisited: bilayer asymmetry and water-exchange kinetics
}

Rapid nerve conduction in the central and peripheral nervous systems (CNS and PNS, respectively) of higher vertebrates is brought about by the ensheathment of axons with myelin, a lipid-rich, multilamellar assembly of membranes. The ability of myelin to electrically insulate depends on the regular stacking of these plasma membranes and on the presence of a number of specialized membrane-protein assemblies in the sheath, including the radial component, Schmidt-Lanterman incisures and the axo-glial junctions of the paranodal loops. The disruption of this fine-structure is the basis for many demyelinating neuropathies in the CNS and PNS. Understanding the processes that govern myelin biogenesis, maintenance and destabilization requires knowledge of myelin structure; however, the tight packing of internodal myelin and the complexity of its junctional specializations make myelin a challenging target for comprehensive structural analysis. This paper describes an examination of myelin from the CNS and PNS using neutron diffraction. This investigation revealed the dimensions of the bilayers and aqueous spaces of myelin, asymmetry between the cytoplasmic and extracellular leaflets of the membrane, and the distribution of water and exchangeable hydrogen in internodal multilamellar myelin. It also uncovered differences between CNS and PNS myelin in their water-exchange kinetics.

\section{Introduction}

The myelin sheath is a complex, multilamellar assembly of oligodendroglial or Schwann-cell plasma membranes that are spirally wrapped around axons, providing insulation and facilitating rapid signal transmission. Although relatively protein-poor compared with metabolically active membranes, myelin displays a surprising amount of heterogeneity, asymmetry and organization into structurally distinct functional domains, including the predominant internodal myelin, Schmidt-Lanterman incisures, the paranodal loops and unique to the CNS - the radial component (Arroyo \& Scherer, 2000; Scherer \& Arroyo, 2002; Debruin \& Harauz, 2007; Trapp $\&$ Kidd, 2004). These and related features have been the subject of intense investigation aimed at determining their normal composition, formation, organization and function. The wide variety of neurological disorders involving myelin provides additional challenges of determining how myelin fine structure is altered in diseases and the functional implications of these changes, and of assessing the extent and quality of structural and functional recovery in therapeutic paradigms.

Myelin structure has typically been investigated using light and electron microscopy (LM and EM, respectively) and X-ray diffraction (XRD). Although each method has its
Received 23 July 2014

Accepted 28 October 2014 
particular merits and limitations (Kirschner \& Blaurock, 1992), XRD is especially useful because it can determine quantitative parameters about the structure of internodal myelin in a volume of unfixed tissue: e.g. the relative amount of myelin, its periodicity, the average membrane-bilayer profile and the packing of its membranes. The use of XRD to analyze fresh, unfixed tissue provides distinct advantages over LM and EM, both because of its higher spatial resolution and because the other techniques may require the use of potentially harsh chemical and/or physical treatments that alter myelin structure (Moretz et al., 1969a,b; Kirschner \& Hollingshead, 1980; Avila et al., 2005).

With XRD, characteristic changes in the electron density of the membrane can be used to determine the localizations and widths of the most distinct structural features of intermodal myelin: the lipid polar headgroup layers, the hydrocarbon core of the bilayer and the aqueous spaces. While this analysis is comparatively straightforward, placing individual membrane components or specific chemical groups within the electrondensity profile is much more difficult owing to the thermal disorder inherent in hydrated bilayers, the similarity in X-ray scattering power of three of the most abundant biological elements $(\mathrm{O}, \mathrm{C}$ and $\mathrm{N})$ and the fact that the profile represents the average of a heterogeneous membrane along the plane of the bilayer and through the stack of membranes (White \& Wiener, 1995). Complete structural determination therefore requires additional biochemical or structural correlates. In diffraction experiments from artificial membrane systems, for example, this problem is addressed by localizing an increase in electron density in the bilayer owing to the specific labelling of membrane components with a heavy atom [e.g. bromine (Franks et al., 1978; Hristova \& White, 1998; Katsaras \& Stinson, 1990; Lytz et al., 1984; McIntosh \& Holloway, 1987; MacNaughtan et al., 1985; Wiener \& White, 1991) or thallium (He et al., 1993)]. Although widely used in the analysis of artificial membranes, this approach would be prohibitively difficult and potentially harmful to myelinated tissue.

Neutron diffraction (ND) can provide a complementary view of the membrane for a more complete understanding of bilayer structure. In contrast to X-rays, which are scattered by atoms in direct proportion to their number of electrons, neutrons are scattered by nuclei. The ability of an atom to scatter neutrons, as measured by its scattering length $(b)$, depends on a complex relationship between its mass and nuclear energy levels. The result is that scattering lengths vary nonlinearly with atomic number and often vary significantly between isotopes of the same element. Owing to the large difference in neutron scattering lengths between deuterium $\left({ }^{2} \mathrm{H}\right.$ or $\left.\mathrm{D}\right)$ and hydrogen $\left({ }^{1} \mathrm{H}\right.$ or $\left.\mathrm{H}\right)\left(0.65 \times 10^{-12} \mathrm{~cm}\right.$ versus $-0.38 \times 10^{-12} \mathrm{~cm}$, respectively; Bacon \& Lonsdale, 1953) and to the fact that these atoms can be substituted for one another isomorphously, one can either highlight or suppress the scatter from particular features of a structure, potentially allowing the determination of molecular or atomic localization in natural membranes such as myelin.

The possibility of studying myelin using neutron diffraction was first demonstrated over 45 years ago (Parsons \& Akers,
1969); however, there have only been a few follow-up studies directly addressing questions of myelin biology: Haywood and Worcester analyzed canine sciatic nerves to demonstrate the capability of a new neutron instrument (Haywood \& Worcester, 1973); Kirschner and coworkers demonstrated hydrogendeuterium contrast variation and $\mathrm{H}_{2} \mathrm{O}-\mathrm{D}_{2} \mathrm{O}$ exchange kinetics in rabbit sciatic nerves (Kirschner et al., 1976); Worcester and Ibel examined contrast variation in rabbit and frog sciatic nerves and presented low-resolution diffraction from rabbit optic nerves in $\mathrm{D}_{2} \mathrm{O}$ (as cited by Worcester, 1976); and Scott and coworkers attempted to determine the localization of deuterium-labelled cholesterol in rat sciatic nerves (Scott et al., 1980). Although foundational, this research was severely limited by early neutron technology. Experiments required the use of large samples obtained from relatively large animals (i.e. dogs and humans) or bundles of nerves from smaller animals (i.e. rabbits and rats), multiple detector positions and exposure times as long as several days. For ND to be a useful technique for myelin research today, it must be rapid and compatible with single myelinated nerves from animals as small as mice, for which an ever-expanding library of neurologically relevant mutants exists and which therefore provide numerous therapeutic models. In the current paper, which presents a timely revisit of ND from myelin, we describe novel data from CNS myelin, improved data from PNS myelin, and water-exchange kinetics in both, and we discuss some immediate future possibilities for the analysis of myelin by neutron diffraction.

\section{Materials and methods}

\subsection{Specimens}

For neutron diffraction experiments, animals were housed at the Biomedical Facility at the European Synchrotron Radiation Facility, Grenoble, France, where all procedures were carried out. Optic nerves, spinal cords and sciatic nerves were obtained from mature C57BL/6J or C57BL/6 × 129S3/ SvImJ mice (4-12 months of age; obtained from Charles River Laboratories, L'Arbresle, France, or provided by Dr A. Gow, Wayne State University Medical School) and Fischer (F344/ IcoCrl) rats (four months of age; Charles River Laboratories) that had been sacrificed using isoflurane followed by decapitation. Spinal cords were routinely bisected sagittally before analysis. All samples were tied off at both ends with a silk suture and maintained in Tris-buffered saline (TBS; $5 \mathrm{~m} M$ Tris base, $154 \mathrm{mM} \mathrm{NaCl}, \mathrm{pH} / \mathrm{pD}$ 7.4) of varying $\mathrm{D}_{2} \mathrm{O}$ content (0$100 \%$ ) until subsequent analysis. The knots on spinal cord segments were typically stabilized using cyanoacrylate adhesive because of the delicate nature of the tissue. For X-ray diffraction experiments, animals were housed and all procedures were carried out at the Boston College Animal Care Facility. Sciatic nerves and spinal cords were isolated from mature C57BL/6J mice (four months of age; obtained from Jackson Laboratory, Bar Harbor, Maine, USA) that had been sacrificed using $\mathrm{CO}_{2}$ asphyxiation and decapitation. Nerves were equilibrated against phosphate-buffered saline (PBS; 
$5 \mathrm{~m} M$ sodium phosphate, $154 \mathrm{~m} M \quad \mathrm{NaCl}, \mathrm{pH} / \mathrm{pD}$ 7.4) containing either 0 or $100 \% \mathrm{D}_{2} \mathrm{O}$. All animal procedures were conducted in accordance with protocols approved by the Institutional Animal Care and Use Committees of the respective institutions.

\subsection{Neutron diffraction}

Neutron diffraction experiments were carried out on the D16 instrument at the Institut Laue-Langevin, Grenoble, France. To optimize sample illumination and angular resolution in the horizontal direction, we used two pairs of collimating slits. The resulting beam size at the sample was typically $1.5 \mathrm{~mm}$ (horizontal) $\times 15 \mathrm{~mm}$ (vertical). The neutron wavelength was $4.75 \AA$. Diffraction patterns were collected using the Millimeter Resolution Large Area Neutron Detector (MiLAND), a high-pressure ${ }^{3} \mathrm{He}$ neutron detector with an area of $320 \times 320 \mathrm{~mm}$ and a 'pixel' resolution of $1 \times$ $1 \mathrm{~mm}$. The sample-to-detector distances were either 870 or $900 \mathrm{~mm}$. All neutron diffraction experiments were performed at ambient temperature $\left(\sim 25^{\circ} \mathrm{C}\right)$ and pressure. For static measurements, samples were loaded into thin-walled quartz capillary tubes (Charles Supper Company, Natick, Massachusetts, USA) filled with TBS containing a known fraction of $\mathrm{D}_{2} \mathrm{O}$ and sealed with wax and enamel. Exposure times in static experiments ranged from 1 to $5 \mathrm{~h}$. For $\mathrm{H}_{2} \mathrm{O}-\mathrm{D}_{2} \mathrm{O}$ exchange experiments, the sample to be perfused was loaded into a Suprasil EPR tube (Wilmad-Labglass, Vineland, New Jersey, USA; inner diameter, $2 \mathrm{~mm}$; outer diameter, $3 \mathrm{~mm}$ ) that had been epoxied into a specially designed aluminium or Lucite yoke. Each end of the yoke had a stainless-steel pin for holding, via a tight-fitting O-ring, the suture attached to the end of the sample. The sample yoke was then sealed via O-rings into a Lucite perfusion yoke that was connected via Tygon tubing to a buffer reservoir and a peristaltic pump. The pump provided continuous replacement, at a flow rate of $0.5 \mathrm{ml} \mathrm{s}^{-1}$, of the fluid surrounding the sample.

Diffraction data for $\mathrm{H}_{2} \mathrm{O}-\mathrm{D}_{2} \mathrm{O}$ exchange experiments were collected as a tandem series of increasingly long exposures: typically $12 \times 5 \mathrm{~s}, 12 \times 10 \mathrm{~s}, 12 \times 15 \mathrm{~s}, 50 \times 30 \mathrm{~s}$ and $30 \times$ $1 \mathrm{~min}$ for a total exposure of $\sim 1 \mathrm{~h}$. Longer exposures were routinely collected from each sample before and after exchange experiments to collect high signal-to-noise diffraction patterns and to ensure sample integrity; during exchange experiments, the intensity of the strong second-order reflection was sufficient to obtain time-resolved data. For most exchange experiments, we positioned the detector so that it could detect a range in $q$ from -0.11 to $0.37 \AA^{-1}$, which included the direct beam and each of the two second-order reflections near $\pm 0.07 \AA^{-1}$ (PNS) or $\pm 0.08 \AA^{-1}$ (CNS). This allowed improved counting statistics at low exposure times through the integration of the pair of unique second-order reflections. Our addition of a neutron-translucent, $250 \mu \mathrm{m}$ thick, cadmium beamstop to attenuate the transmitted direct beam enabled us to collect sample transmissions during each data acquisition, so that the observed intensities at each time point in an exchange experiment could be properly corrected for transmission (which continuously changes during $\mathrm{H}_{2} \mathrm{O}-$ $\mathrm{D}_{2} \mathrm{O}$ exchange) and background.

\subsection{Neutron data refinement}

All data refinement was performed using the ILL inhouse software LAMP (http://www.ill.eu/instruments-support/ computing-for-science/data-analysis). Firstly, the diffraction patterns were normalized to the incident neutron beam flux to account for variations in beam intensity and exposure time between samples. Secondly, they were normalized to a detector-calibration file containing the flat incoherent signal from water, which was used to correct the observed intensities for pixel efficiency and solid angle. Thirdly, they were corrected for the attenuation of the direct beam by the sample (transmission). Finally, background patterns from empty quartz capillaries or EPR tubes were collected and subtracted from each sample pattern. The corrected patterns were integrated along the fibre axis in either a window or azimuthally, depending on the sample type, to produce one-dimensional diffraction patterns. These resulting patterns were analyzed using either LAMP or PeakFit (Systat Software Inc.). The background was subtracted using local regression with Gaussian weighting. Reflections were fitted using asymmetric logistic peaks. The myelin period $(d)$ was calculated from Bragg's Law,

$$
d=\frac{h \lambda}{2 \sin \theta},
$$

where $h$ is the Bragg order for the observed reflection, $\lambda$ is the neutron wavelength and $\theta$ is half of the scattering angle. The scattering vector $q$ was calculated using

$$
q=\frac{2 \pi}{d} .
$$

For samples analyzed at $\geq 43 \% \mathrm{D}_{2} \mathrm{O}$, the integrated intensity $\left(I_{h}\right)$ of the fourth-order reflection was reduced by $I_{2}^{2} / I_{0}$ to remove the contribution of the doubly scattered strong second-order reflection (Kirschner et al., 1976). In our experiments, the second-order intensity in $100 \% \mathrm{D}_{2} \mathrm{O}$ was $<0.1 \%$ that of the incident beam. Structure-factor amplitudes $\left(\left|F_{h}\right|\right)$ were calculated from corrected peak intensities by

$$
\left|F_{h}\right|=\left(h I_{h}\right)^{1 / 2}
$$

according to the beam geometry. For most samples, secondorder structure factors were linearized versus $\% \mathrm{D}_{2} \mathrm{O}$ and normalized to unity at $100 \% \mathrm{D}_{2} \mathrm{O}$ to correct for small differences in sample size and orientation. The other structure factors were scaled based on the relative intensity of their second-order structure factors to the expected $F_{2}$ at that $\% \mathrm{D}_{2} \mathrm{O}$. In the absence of a strong second-order reflection (i.e. at low $\% \mathrm{D}_{2} \mathrm{O}$ ), the fourth-order reflection was used instead. Consequently, any potential nonlinearity owing to extinction was removed from the dependence of $F_{h}$ on $\% \mathrm{D}_{2} \mathrm{O}$ (Caspar \& Phillips, 1976). Linear regression analysis was then performed between $\left|F_{h}\right|$ and $\% \mathrm{D}_{2} \mathrm{O}$. Phases were assigned to structure factors according to Kirschner et al. (1976). Average neutron 
scattering density profiles were calculated using $F_{h}$ derived from regression models with

$$
\rho(r)=\frac{2}{d} \sum_{h=1}^{h_{\max }} F_{h} \cos \left(\frac{2 \pi h r}{d}\right),
$$

where $r$ is the radial distance along the repeating unit (myelin membrane pair). Profiles were then scaled based on expected neutron scattering densities for myelin (Kirschner et al., 1976; Kirschner, 1974). Uncertainty was modelled into the scattering density profiles according to Franks \& Lieb (1979) using

$$
\Delta \rho(r)=2\left[\sum_{h=1}^{h_{\max }}\left(\frac{F_{h}}{N_{h}^{1 / 2}}\right)^{2} \cos ^{2}\left(\frac{2 \pi h r}{d}\right)\right]^{1 / 2},
$$

with the modification that Poisson counting statistics $\left(F_{h} / N_{h}^{1 / 2}\right)$, where $N_{h}$ is the number of counts observed for a reflection of $h$ th order, were used in place of $\Delta F_{h}$ because of the lack of multiple measurements for some reflections. For unobserved reflections, counting statistics were extrapolated from measured values using linear regression.

\subsection{X-ray diffraction}

X-ray diffraction experiments were performed as described previously (Avila et al., 2005). Briefly, sciatic nerves and

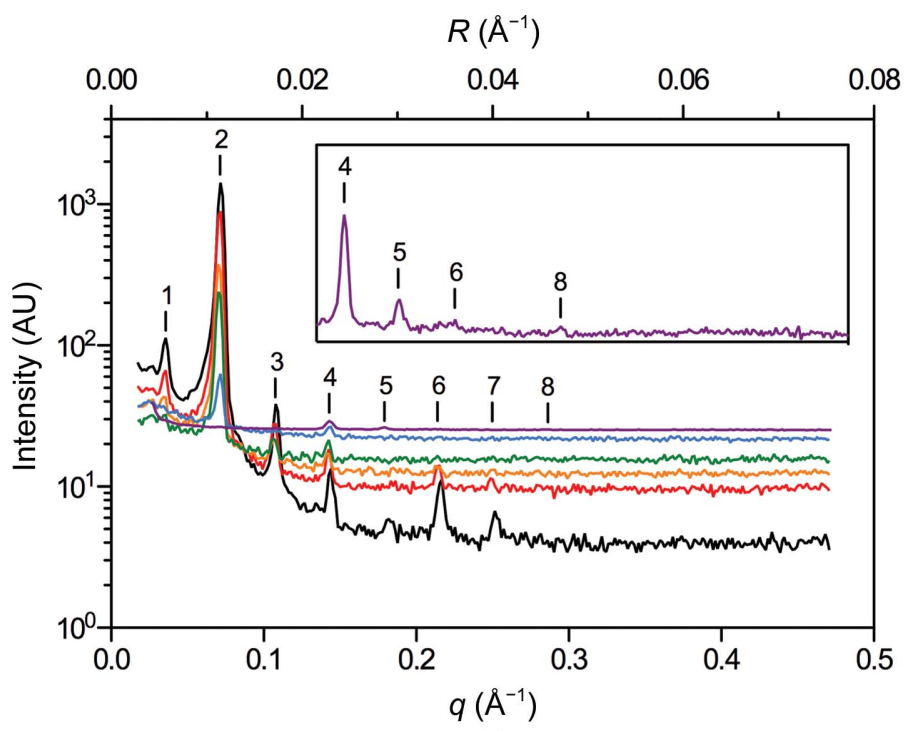

$(a)$

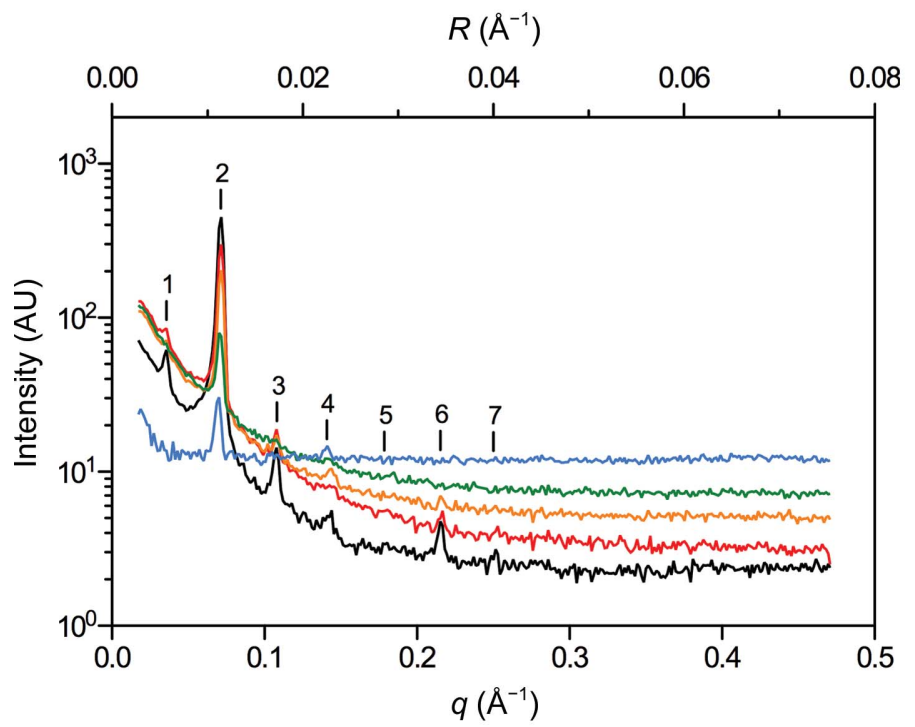

(c)

$\mathrm{D}_{2} \mathrm{O}$

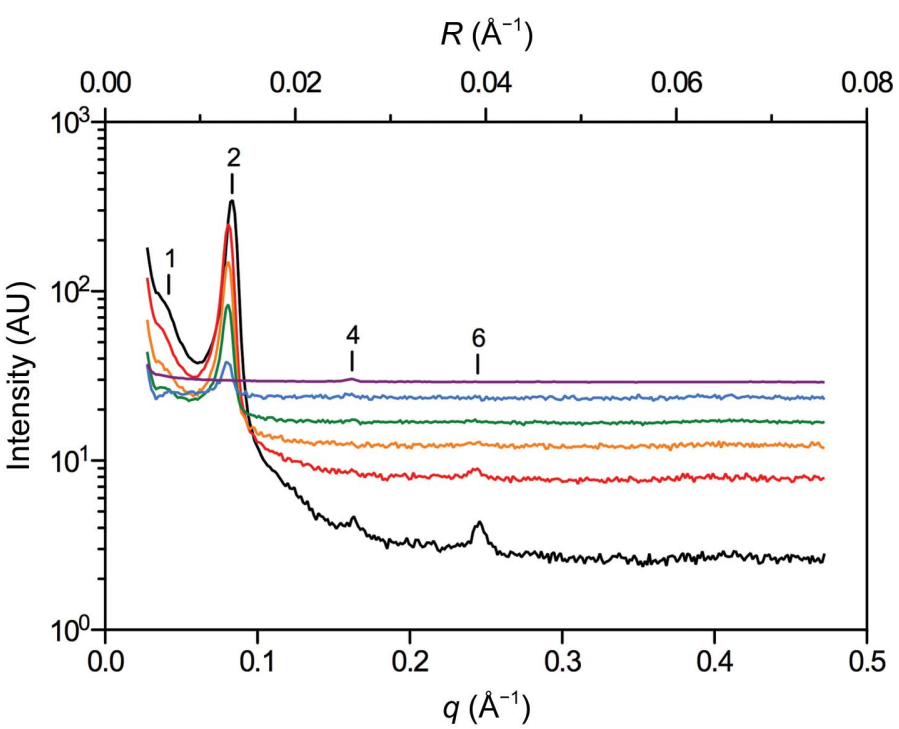

(b)

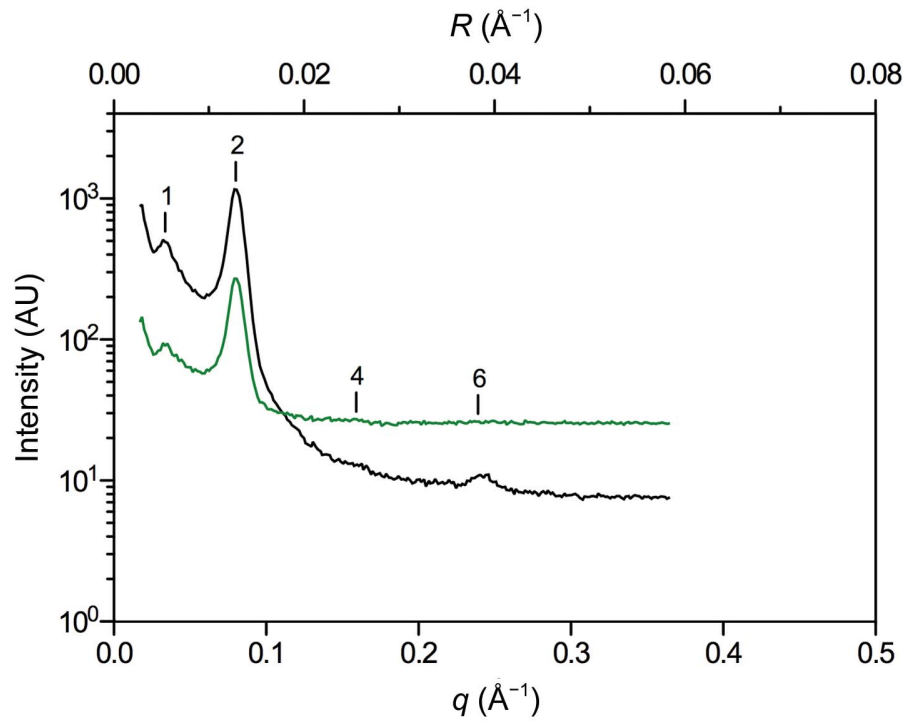

$(d)$

Figure 1

Neutron diffraction patterns from $(a)$ rat sciatic nerves, $(b)$ rat optic nerves, $(c)$ mouse sciatic nerves and $(d)$ mouse spinal cords equilibrated against 0 $100 \% \mathrm{D}_{2} \mathrm{O}$-saline. Scattering intensity is plotted against both the scattering vector $q\left(2 \pi / d ; \AA^{-1}\right)$ and the reciprocal coordinate $R\left(1 / d ; \AA^{-1}\right)$. Bragg orders are indicated with numerals above the reflections. The inset in $(a)$ is expanded along the $y$ axis to more clearly show the additional Bragg orders recorded in $100 \% \mathrm{H}_{2} \mathrm{O}$. 
sagitally bisected segments of spinal cord were isolated from C57BL/6J mice and equilibrated against either $\mathrm{D}_{2} \mathrm{O}$-saline or $\mathrm{H}_{2} \mathrm{O}$-saline. They were then loaded into thin-walled quartz capillaries containing the same solution and sealed. X-ray diffraction was performed using nickel-filtered, single-mirror focused $\mathrm{Cu} K \alpha$ radiation from a fine-line source on a $3.0 \mathrm{~kW}$ Rigaku X-ray generator operated at $40 \mathrm{kV}$ and $10 \mathrm{~mA}$. Exposure times were $30 \mathrm{~min}$. Diffraction patterns were collected using a linear, position-sensitive detector (Molecular Metrology, Northampton, Massachusetts, USA) and were analyzed using PeakFit. All X-ray diffraction experiments were performed at ambient temperature $\left(\sim 22^{\circ} \mathrm{C}\right)$ and pressure. The myelin period was calculated from the positions of the intensity maxima in the diffraction patterns. The relative amount of myelin $[\mathrm{M} /(\mathrm{M}+\mathrm{B})]$ was calculated by comparing the integrated intensity of all maxima with the total scatter, including the background and excluding small-angle scatter around the beamstop and wide-angle scatter (Avila et al., 2005). Relative amounts of myelin were then scaled to correct for differences in diffraction intensity originating from lattices with different periods (Kirschner \& Caspar, 1975).

\section{Results and analysis}

\subsection{Neutron diffraction from rat and mouse PNS myelin}

To benchmark current ND capabilities for myelin structure analysis, and because no data have been presented since the original research from the 1970 s, we first examined rat sciatic nerves and compared these results with the early data collected from rabbit peripheral nerves (Kirschner et al., 1976). Although a single rat sciatic nerve ( $<1 \mathrm{~mm}$ in diameter; $>15 \mathrm{~mm}$ in length) is significantly smaller than the bundles of rabbit sciatic nerves previously analyzed (three each of $>1 \mathrm{~mm}$ in diameter), it produced a series of strong Bragg reflections (Fig. 1a) corresponding to an average myelin period of $175.5 \pm$ $1.5 \AA(n=11)$, which is typical for rodent PNS myelin in X-ray diffraction experiments (Kirschner \& Blaurock, 1992).

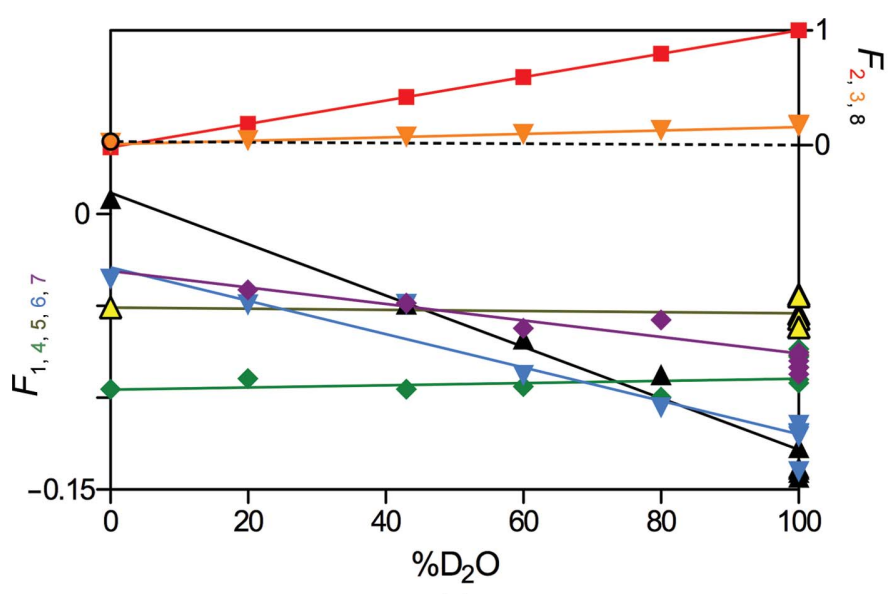

(a)

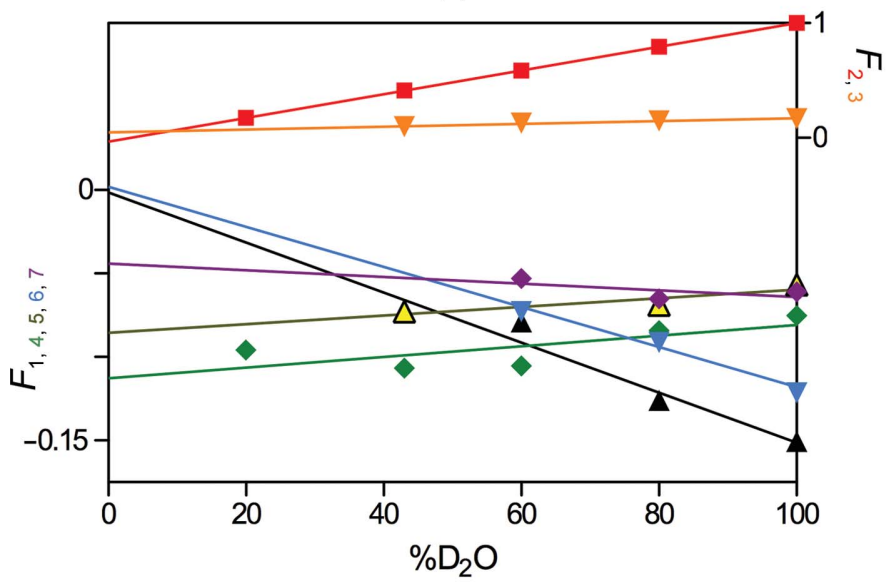

(c)

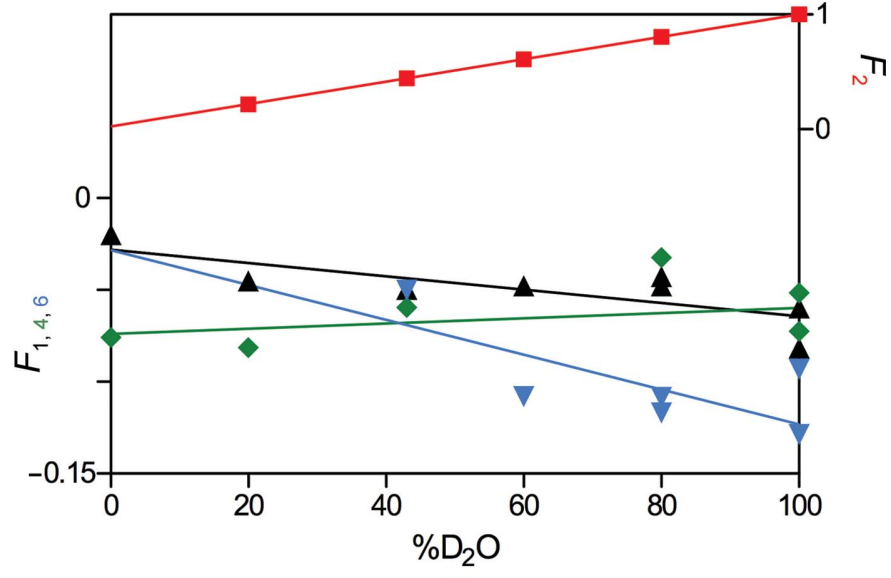

(b)

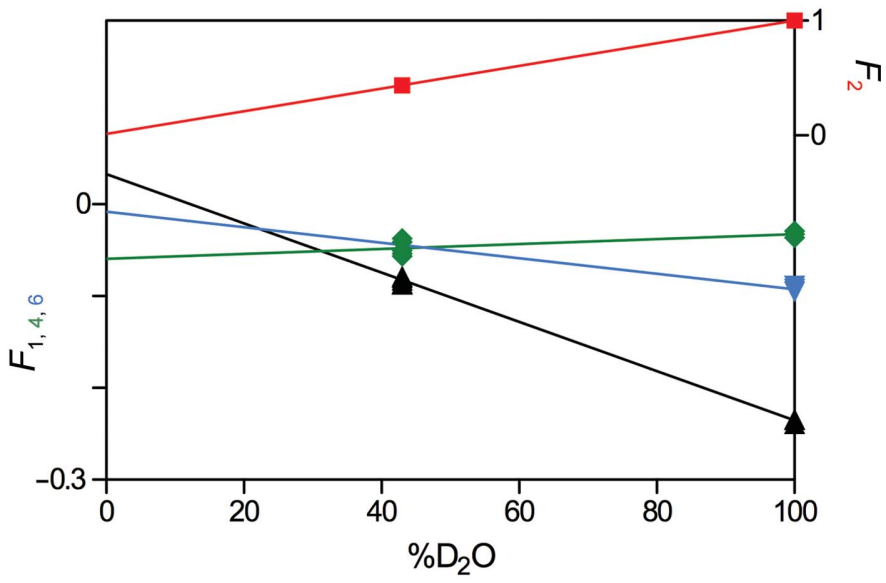

(d)

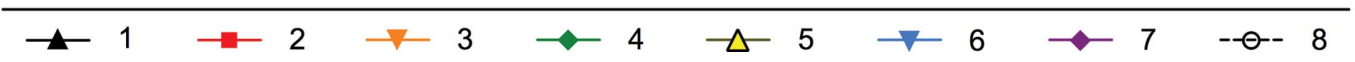

Figure 2

Structure-factor amplitudes with assigned phases versus $\% \mathrm{D}_{2} \mathrm{O}$ for $(a)$ rat sciatic nerves, $(b)$ rat optic nerves, $(c)$ mouse sciatic nerves and $(d)$ mouse spinal cords. Symbols represent experimental replicates. Lines represent the linear dependence of $F_{h}$ on $\% \mathrm{D}_{2} \mathrm{O}$. In the absence of measurements of $F_{8}$ in rat sciatic nerve at multiple concentrations of $\mathrm{D}_{2} \mathrm{O}$, the linear regression of $F_{8}$ versus $\% \mathrm{D}_{2} \mathrm{O}$ was forced through 0 at $100 \% \mathrm{D}_{2} \mathrm{O}$. Similarly, $F_{6}$ for mouse spinal cord was modelled using the single observed reflection at $100 \% \mathrm{D}_{2} \mathrm{O}$-saline and the slope of $F_{6}$ versus $\% \mathrm{D}_{2} \mathrm{O}$ from rat optic nerve. The $y$-axis labels are colour-coded to correspond to the respective data sets. 
Table 1

Structure factors for rat and mouse PNS and CNS myelin versus $\% \mathrm{D}_{2} \mathrm{O}$.

\begin{tabular}{|c|c|c|c|c|c|c|c|}
\hline \multirow[b]{2}{*}{ Sample } & \multirow[b]{2}{*}{ Bragg order $h$} & \multicolumn{6}{|c|}{ Average $F_{h}$ with assigned phase and uncertainty $\dagger$} \\
\hline & & $100 \% \mathrm{D}_{2} \mathrm{O}$ & $80 \% \mathrm{D}_{2} \mathrm{O}$ & $60 \% \mathrm{D}_{2} \mathrm{O}$ & $43 \% \mathrm{D}_{2} \mathrm{O}$ & $20 \% \mathrm{D}_{2} \mathrm{O}$ & $0 \% \mathrm{D}_{2} \mathrm{O}$ \\
\hline \multirow[t]{8}{*}{ Rat sciatic nerve } & 1 & $-0.138(0.002)$ & $-0.087(0.002)$ & $-0.068(0.003)$ & $-0.049(0.004)$ & & $0.009(0.001)$ \\
\hline & 2 & $1.000(0.003)$ & $0.796(0.003)$ & $0.593(0.005)$ & $0.419(0.005)$ & $0.185(0.003)$ & $-0.017(0.001)$ \\
\hline & 3 & $0.169(0.004)$ & $0.129(0.004)$ & $0.096(0.006)$ & $0.069(0.006)$ & $0.039(0.004)$ & $0.017(0.002)$ \\
\hline & 4 & $-0.081(0.004)$ & $-0.100(0.005)$ & $-0.094(0.007)$ & $-0.095(0.007)$ & $-0.090(0.004)$ & $-0.095(0.002)$ \\
\hline & 5 & $-0.054(0.006)$ & & & & & $-0.051(0.002)$ \\
\hline & 6 & $-0.123(0.005)$ & $-0.106(0.006)$ & $-0.088(0.008)$ & $-0.049(0.009)$ & $-0.049(0.005)$ & $-0.036(0.003)$ \\
\hline & 7 & $-0.081(0.006)$ & $-0.058(0.006)$ & $-0.062(0.009)$ & $-0.048(0.010)$ & $-0.041(0.005)$ & \\
\hline & 8 & & & & & & $0.0339(0.003)$ \\
\hline \multirow[t]{4}{*}{ Rat optic nerve } & 1 & $-0.071(0.003)$ & $-0.045(0.003)$ & $-0.048(0.003)$ & $-0.050(0.002)$ & $-0.045(0.004)$ & $-0.020(0.001)$ \\
\hline & 2 & $1.000(0.004)$ & $0.805(0.005)$ & $0.609(0.005)$ & $0.443(0.002)$ & $0.219(0.006)$ & \\
\hline & 4 & $-0.062(0.006)$ & $-0.032(0.006)$ & & $-0.060(0.003)$ & $-0.081(0.008)$ & $-0.076(0.002)$ \\
\hline & 6 & $-0.111(0.007)$ & $-0.113(0.008)$ & $-0.108(0.008)$ & $-0.050(0.004)$ & & \\
\hline \multirow[t]{7}{*}{ Mouse sciatic nerve } & 1 & $-0.151(0.004)$ & $-0.126(0.005)$ & $-0.079(0.004)$ & $-0.072(0.005)$ & & \\
\hline & 2 & $1.000(0.006)$ & $0.794(0.007)$ & $0.587(0.006)$ & $0.412(0.007)$ & $0.175(0.005)$ & \\
\hline & 3 & $0.169(0.007)$ & $0.147(0.008)$ & $0.127(0.008)$ & $0.098(0.009)$ & & \\
\hline & 4 & $-0.075(0.008)$ & $-0.084(0.009)$ & $-0.105(0.009)$ & $-0.107(0.010)$ & $-0.096(0.007)$ & \\
\hline & 5 & $-0.057(0.009)$ & $-0.069(0.010)$ & & $-0.073(0.012)$ & & \\
\hline & 6 & $-0.122(0.010)$ & $-0.091(0.011)$ & $-0.073(0.011)$ & & & \\
\hline & 7 & $-0.061(0.010)$ & $-0.065(0.012)$ & $-0.053(0.012)$ & & & \\
\hline \multirow[t]{4}{*}{ Mouse spinal cord } & 1 & $-0.236(0.002)$ & & & $-0.083(0.001)$ & & \\
\hline & 2 & $1.000(0.003)$ & & & $0.438(0.002)$ & & \\
\hline & 4 & $-0.033(0.006)$ & & & $-0.048(0.004)$ & & \\
\hline & 6 & $-0.092(0.007)$ & & & & & \\
\hline
\end{tabular}

$\dagger$ Uncertainty in $F_{h}$ is denoted by counting statistics (values in parentheses).

Varying the $\mathrm{D}_{2} \mathrm{O}$ content of the sample resulted in significant changes in the neutron diffraction patterns. With decreasing $\% \mathrm{D}_{2} \mathrm{O}$ the intensities of the observed reflections generally decreased, although not uniformly among Bragg orders, and the incoherent background level rose as the amounts of hydrogen $\left({ }^{1} \mathrm{H}\right)$ increased in the sample. Data collected at low $\% \mathrm{D}_{2} \mathrm{O}$ generally required higher counting times to obtain reasonable counting statistics. We observed seven reflections from rat sciatic nerve in $100 \% \mathrm{H}_{2} \mathrm{O}$-saline (Bragg orders 1-6 and 8; Fig. 1a, inset). Otherwise, Bragg orders 1-7 were typi- cally observed, including the occasional presence of the fifthorder reflection which had previously been unresolved even at high $\% \mathrm{D}_{2} \mathrm{O}$ (Kirschner et al., 1976). The relative intensities of the reflections were consistent with previous findings, particularly the dominant second-order reflection in high $\% \mathrm{D}_{2} \mathrm{O}$, which is accounted for by the two distinct water layers (i.e. the cytoplasmic and extracellular compartments) within the multilamellar array. As expected, the calculated structure factors varied linearly with the concentration of $\mathrm{D}_{2} \mathrm{O}$ in the sample (Franks \& Lieb, 1979; Fig. 2a, Table 1).
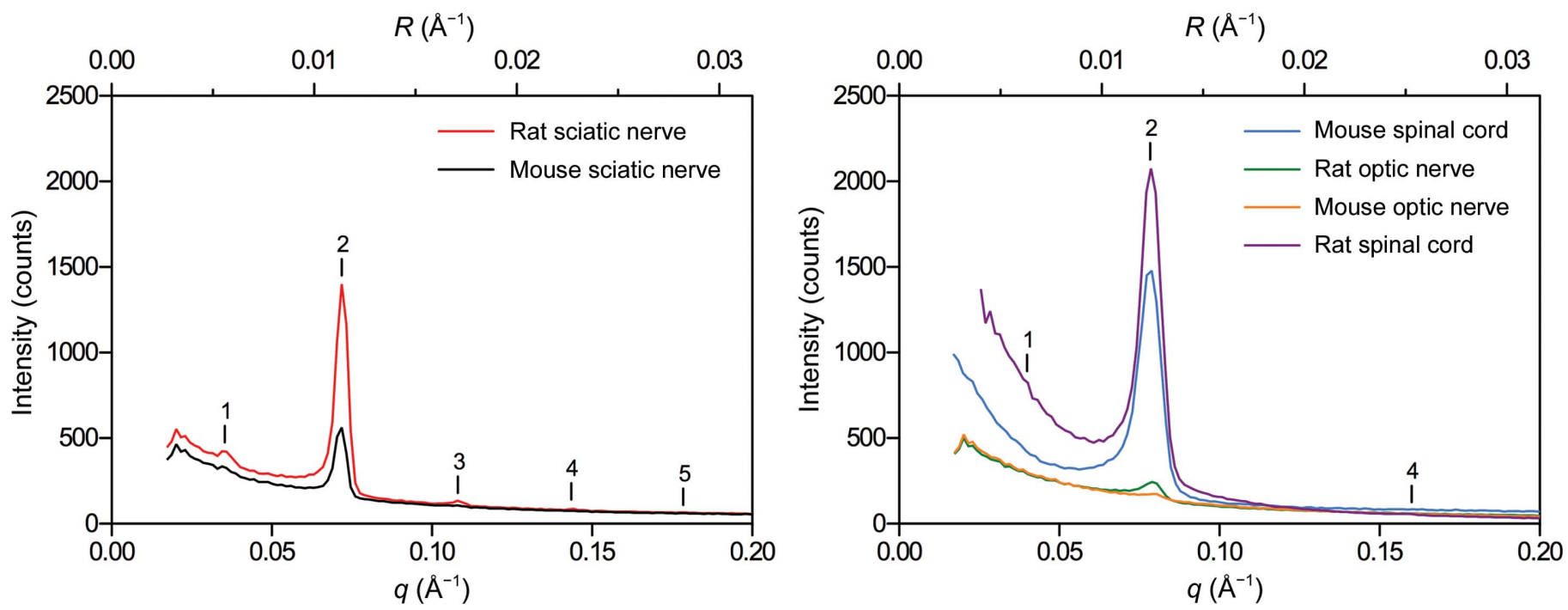

Figure 3

Comparison of neutron diffraction from rat and mouse (left) peripheral and (right) central nervous system tissue. Neutron diffraction patterns have only been corrected for detector efficiency, solid angle and exposure time to demonstrate the relative intensities of the second-order Bragg reflection from the respective samples. Scattering intensity is plotted against both the scattering vector $q\left(\AA^{-1}\right)$ and the reciprocal coordinate $R\left(\AA^{-1}\right)$. Bragg orders are indicated with numerals above the reflections. 
The limit of recording ND from PNS myelin was explored by examining even smaller samples: nerves dissected from mice. Mouse sciatic nerves $(<0.5 \mathrm{~mm}$ in diameter; $>15 \mathrm{~mm}$ in length) equilibrated against buffered saline containing varying amounts of $\mathrm{D}_{2} \mathrm{O}$ yielded reflections corresponding to an average myelin period of $175.3 \pm 2.2 \AA(n=5$; Fig. $1 c)$. Similar to rat PNS myelin, the second-order reflection dominated at high $\% \mathrm{D}_{2} \mathrm{O}$. Lesser contributions from Bragg orders 1 and 3-7 were also observed. Diffraction from mouse sciatic nerves was significantly weaker than that from rat sciatic nerves; $I_{2}$ for mouse nerves was about one-third of that from rat nerves (Fig. 3). Nonetheless, analyzable data were collected even at low $\% \mathrm{D}_{2} \mathrm{O}$, and the same linear relationship between $F_{h}$ and $\% \mathrm{D}_{2} \mathrm{O}$ was observed (Fig. $2 c$, Table 1 ).

\subsection{Neutron diffraction from rat and mouse CNS myelin}

Previous work suggested that CNS myelin had only a limited capacity to provide meaningful neutron scattering data (Worcester, 1976). To determine the extent to which ND could be used to analyze CNS myelin, we examined rat optic nerve and spinal cord ( $2 \mathrm{~mm}$ in diameter; $>15 \mathrm{~mm}$ in length), followed by mouse optic nerve and spinal cord. Because of their small size $(\sim 0.5 \mathrm{~mm}$ in diameter; $<10 \mathrm{~mm}$ in length), we expected rat optic nerves to diffract much more weakly than sciatic nerves. It also has been previously demonstrated using XRD (Avila et al., 2005 and subsequently by our own ND experiments) that diffraction from CNS myelin is generally of lower quality than that from PNS myelin because of the smaller coherent domain size (fewer layers of myelin) and increased disorder in membrane packing in CNS myelin

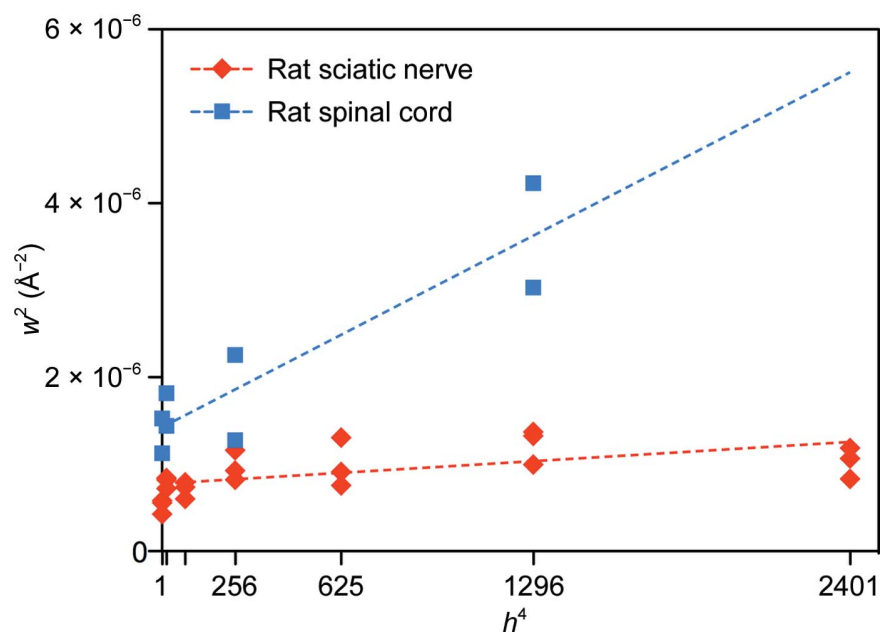

Figure 4

Comparison between rat spinal cord (CNS) and sciatic nerve (PNS) myelin packing disorder and the crystallinity of myelin. The square of the full-width at half-maximum for each reflection $\left(w^{2}\right)$ is plotted against the fourth power of the Bragg order $\left(h^{4}\right)$. Dashed lines behind the data represent linear least-squares fits for spinal cord (blue) and sciatic nerve (red). The slope of each line is directly related to the amount of membrane-packing disorder in the tissue, while the intercept is inversely proportional to the crystallinity (the coherence length or the average number of layers of myelin; Inouye et al., 1989). The coherence lengths for spinal cord and sciatic nerve were approximately eight and 12 repeats (membrane pairs), respectively.
(Fig. 4; Inouye et al., 1989). We found, however, that diffraction from rat optic nerves was of sufficient intensity and quality for meaningful analysis, even at low $\% \mathrm{D}_{2} \mathrm{O}$ (Fig. 1b). Depending on the $\mathrm{D}_{2} \mathrm{O}$ content of the nerves, Bragg orders 1 , 2,4 and 6 were visible and indexed to a myelin period of 155.0 $\pm 1.1 \AA(n=8)$, typical of rodent CNS myelin (Kirschner \& Blaurock, 1992). The second-order Bragg reflection dominated the patterns at high $\% \mathrm{D}_{2} \mathrm{O}$ (with $\sim 15 \%$ of the intensity of the second-order reflection from rat sciatic nerve), indicating the presence - similar to PNS myelin - of two distinct water layers within the multilamellar array. Very weak first-, fourth- and sixth-order reflections were also detected. In contrast to the diffraction from PNS myelin, the absence of the higher odd-order reflections ( $h=3,5$ and 7) from CNS myelin demonstrates that the aqueous spaces at the extracellular and cytoplasmic appositions have similar widths. As for PNS myelin, the calculated structure factors varied linearly with $\% \mathrm{D}_{2} \mathrm{O}$ (Fig. 2b, Table 1).

Although routinely used for X-ray diffraction (see, for example, Avila et al., 2005), mouse optic nerves $(<0.5 \mathrm{~mm}$ in diameter; $\sim 5 \mathrm{~mm}$ in length) diffracted neutrons very poorly even in $100 \% \mathrm{D}_{2} \mathrm{O}$-saline, yielding a faint first-order reflection and a second-order reflection that was $<5 \%$ of the intensity of that of rat sciatic nerve (Fig. 3). At $20 \% \mathrm{D}_{2} \mathrm{O}$-saline (not shown), measurable diffraction was not detected. By contrast, diffraction from segments of bisected spinal cord $(\sim 1.5 \mathrm{~mm}$ in diameter; $>15 \mathrm{~mm}$ in length; Fig. $1 d$ ) was strong, with the intensity of the dominant second-order reflection being approximately twofold more intense than that of rat sciatic nerve under identical conditions (Fig. 3). Weak but distinct Bragg orders 1, 4 and 6 were also observed. The average myelin period for mouse spinal cord was $156.3 \pm 0.6 \AA(n=8)$. Again, the absence of higher odd-order reflections demonstrated the similar widths of the cytoplasmic and extracellular appositions, which has been demonstrated by XRD. The linear relationship between $F_{h}$ and $\% \mathrm{D}_{2} \mathrm{O}$ for mouse spinal cord is shown in Fig. $2(d)$ and Table 1.

\subsection{Structure of CNS and PNS myelin}

Neutron scattering density profiles were calculated for myelin from rat sciatic and optic nerves and mouse sciatic nerves and spinal cords (Fig. 5). For both PNS (Figs. $5 a$ and $5 c$ ) and CNS myelin (Figs. $5 b$ and $5 d$ ) at high $\% \mathrm{D}_{2} \mathrm{O}$, two regions of high neutron scattering density characterized the profiles, centred at $r=0$ and $r=0.5 d$ and corresponding to the two distinct aqueous spaces within myelin: the cytoplasmic and extracellular compartments, respectively. As $\mathrm{D}_{2} \mathrm{O}$ was replaced with $\mathrm{H}_{2} \mathrm{O}$, these spaces displayed dramatic changes in scattering density owing to the high proportion of exchangeable hydrogen in water and in other constituents. Between this pair of aqueous compartments were regions of relative constancy that were largely unaffected by alterations in H/D content. These stable regions, near $r=0.25 d$ and $r=0.75 d$, correspond to the hydrocarbon layers in the membrane, which exclude water and are rich in nonexchangeable hydrogen. At $0 \% \mathrm{D}_{2} \mathrm{O}$, the scattering density from the aqueous layers 
decreased sufficiently to reveal four distinct peaks (in the membrane pair, from 0 to $d$ ) corresponding to the lipid polar groups, which are relatively water-poor and hydrogen-poor and rich in more strongly scattering phosphorus, carbon and oxygen. Across all samples, and especially in rat PNS myelin, a shoulder was observed in the extracellular leaflet of the bilayer, proximal to the lipid polar group region. This asymmetry in neutron scattering density within the bilayer is consistent with the postulated enrichment of cholesterol in the extracellular leaflet. The steroid nucleus of cholesterol has a higher neutron scattering density $\left(0.07 \times 10^{11} \mathrm{~cm}^{-2}\right)$ than stiffchain hydrocarbon $\left(-0.01 \times 10^{11} \mathrm{~cm}^{-2}\right)$ (Kirschner, 1974), which could account for its detection here.

The dimensions of the bilayers and intermembrane spaces were consistent with the measurements from previous XRD experiments. For both CNS and PNS samples, the size of the bilayer (determined by the distance from headgroup peak to headgroup peak) ranged from 40 to $46 \AA$, which is lower than the XRD measurements (where it is typically $46-47 \AA$ ), probably owing to the mixed contributions of the hydrogen-

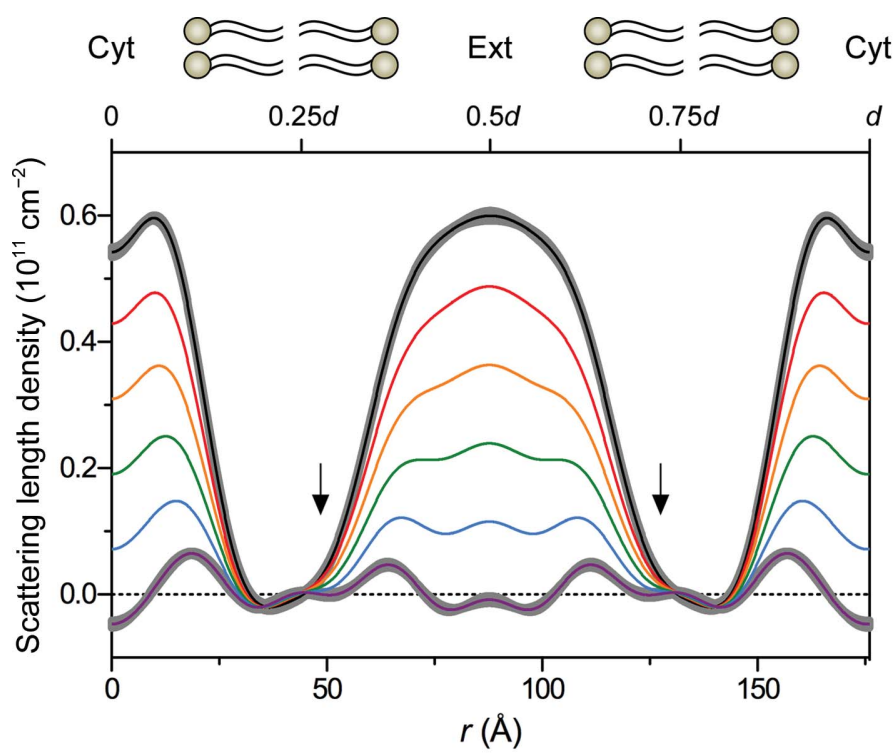

(a)

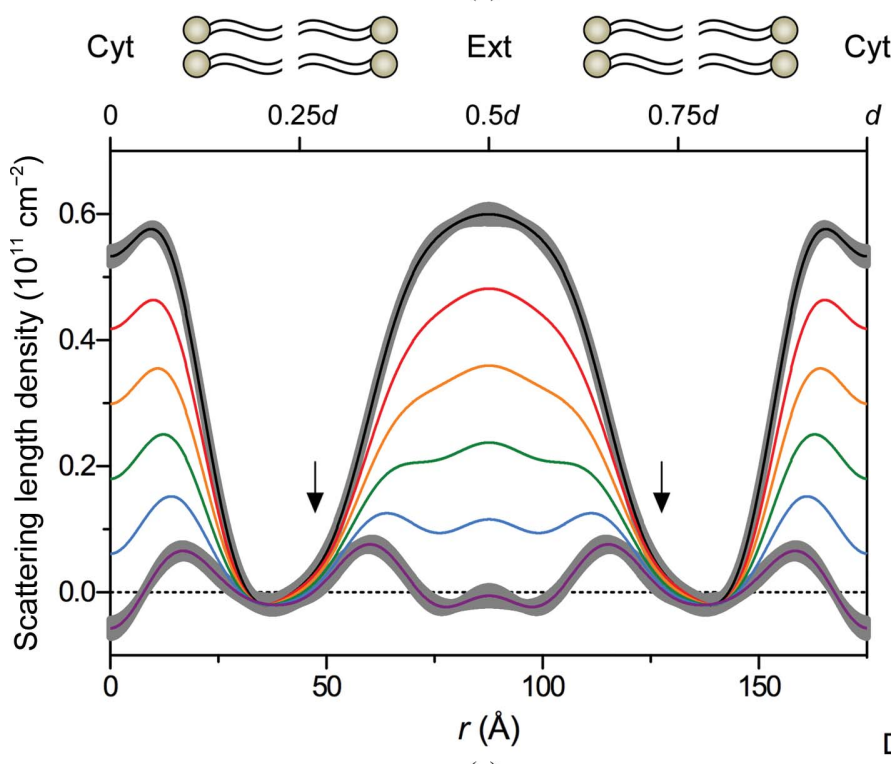

(c)

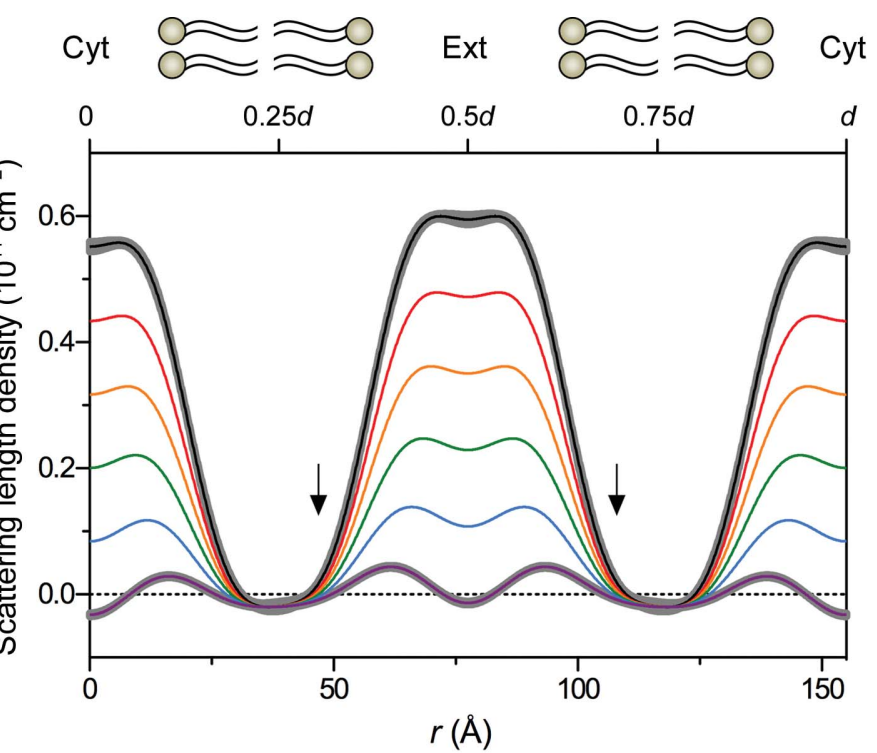

(b)

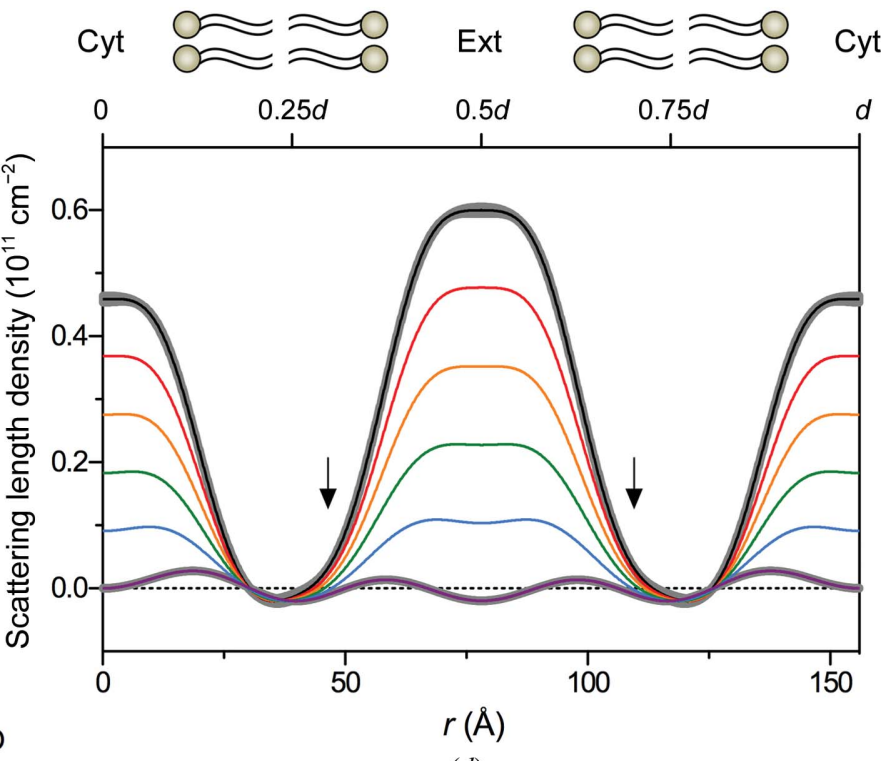

$(d)$

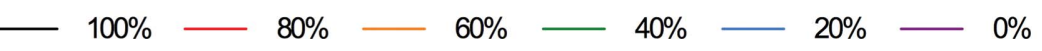

Figure 5

Neutron scattering length density profiles from $(a)$ rat sciatic nerves, $(b)$ rat optic nerves, $(c)$ mouse sciatic nerves and $(d)$ mouse spinal cords in $0-100 \%$ $\mathrm{D}_{2} \mathrm{O}$-saline. Scattering length density is plotted against radial distance $r$, with the centre of the cytoplasmic apposition at $r=0$. For clarity in the bilayer regions, uncertainty (grey borders) was included only for the profiles calculated for myelin in 0 and $100 \% \mathrm{D}_{2} \mathrm{O}$-saline. The arrow indicates the higher level of neutron scattering density in the extracellular half of the bilayer, which is proposed to relate to an asymmetric distribution of cholesterol. For each panel, the upper $x$ axis indicates the positions of $0.25 d, 0.5 d, 0.75 d$ and $d$. 
Table 2

Relaxation times for $\mathrm{H}_{2} \mathrm{O}-\mathrm{D}_{2} \mathrm{O}$ exchange in rat and mouse PNS and CNS myelin.

\begin{tabular}{llrr}
\hline & $\begin{array}{l}\text { Relaxation } \\
\text { time } \tau(\min )\end{array}$ & High to low $\% \mathrm{D}_{2} \mathrm{O}$ & Low to high $\% \mathrm{D}_{2} \mathrm{O}$ \\
\hline Rat sciatic nerve & $\tau_{1}$ & $3.17 \pm 0.46(n=3)$ & $3.71 \pm 0.39(n=3)$ \\
Rat optic nerve & $\tau_{1}$ & $3.97 \pm 1.04(n=5)$ & $4.75 \pm 1.43(n=2)$ \\
& $\tau_{2}$ & $0.44 \pm 0.20(n=4)$ & $0.67(n=1)$ \\
Mouse sciatic nerve & $\tau_{1}$ & $1.72(n=1)$ & $2.47(n=1)$ \\
Mouse spinal cord & $\tau_{1}$ & $5.84 \pm 1.15(n=6)$ & $7.48 \pm 1.11(n=6)$ \\
& $\tau_{2}$ & $0.67 \pm 0.27(n=6)$ & $0.71 \pm 0.03(n=6)$ \\
\hline
\end{tabular}

poor phosphates, glycerol backbones and fatty-acid ester linkages in the headgroup region (Franks \& Lieb, 1979). The cytoplasmic compartments in all samples had similar widths, ranging from 32 to $37 \AA$, with no consistent differences between the PNS and CNS. However, the extracellular compartment varied significantly between the CNS and PNS, with the values of $32-40 \AA$ for the CNS being similar to the cytoplasmic compartment width, whereas expanded values of 47-55 A were measured in the PNS. The observed differences

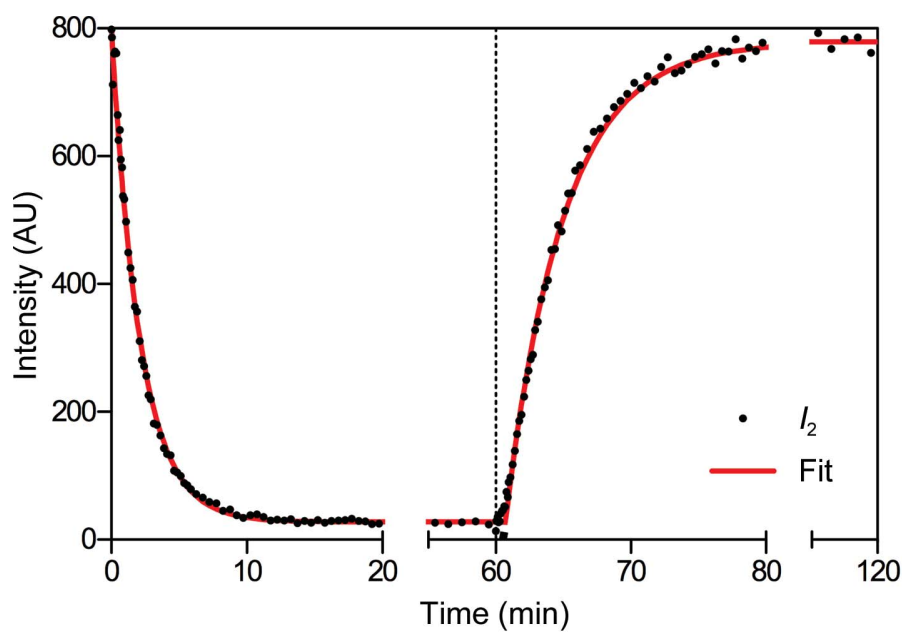

(a)

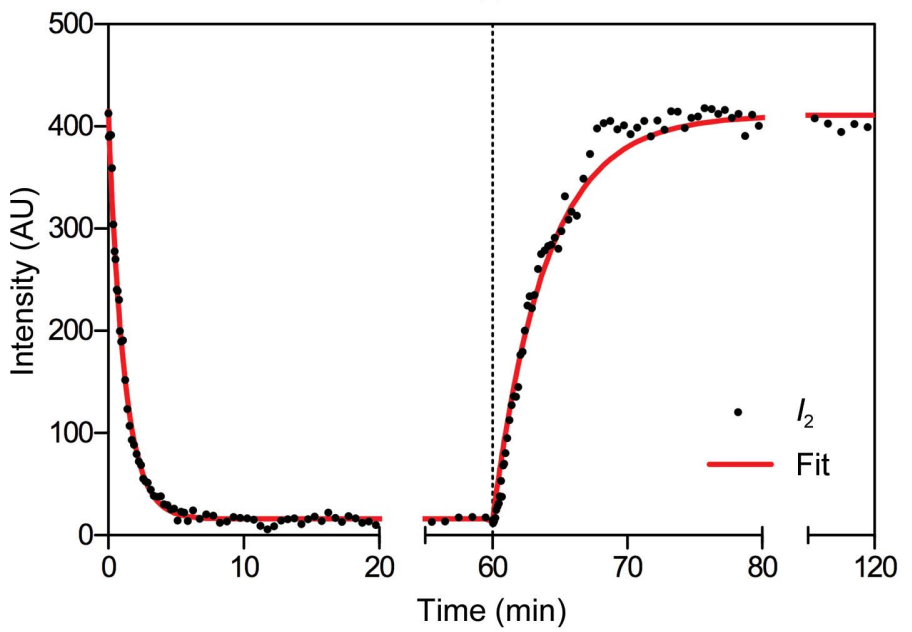

(c)

Figure 6 between rat and mouse myelin structures most likely result from differences in data quality rather than interspecies differences. For example, the relatively high scattering density of the extracellular compartment in mouse spinal cord (Fig. 1d) compared with that of other samples probably comes from poor separation of the broad first-order reflection from the low-angle scatter near the beamstop, which may be improved in the future by using a narrower beam or thinner samples.

\subsection{Hydrogen-deuterium exchange kinetics in myelin}

To probe the insulative properties of myelin, as indicated by the accessibility of water and mobile ions to its multilamellar arrays, we measured water-exchange kinetics in rodent PNS and CNS myelin. Nervous-system tissue that had been equilibrated against buffered saline containing a known concentration of $\mathrm{D}_{2} \mathrm{O}$ was loaded into the perfusion chamber and continuously flushed in situ with saline containing a different concentration of $\mathrm{D}_{2} \mathrm{O}$. Short, serial exposures were collected during perfusion, and the extent of $\mathrm{H}_{2} \mathrm{O}-\mathrm{D}_{2} \mathrm{O}$ exchange was

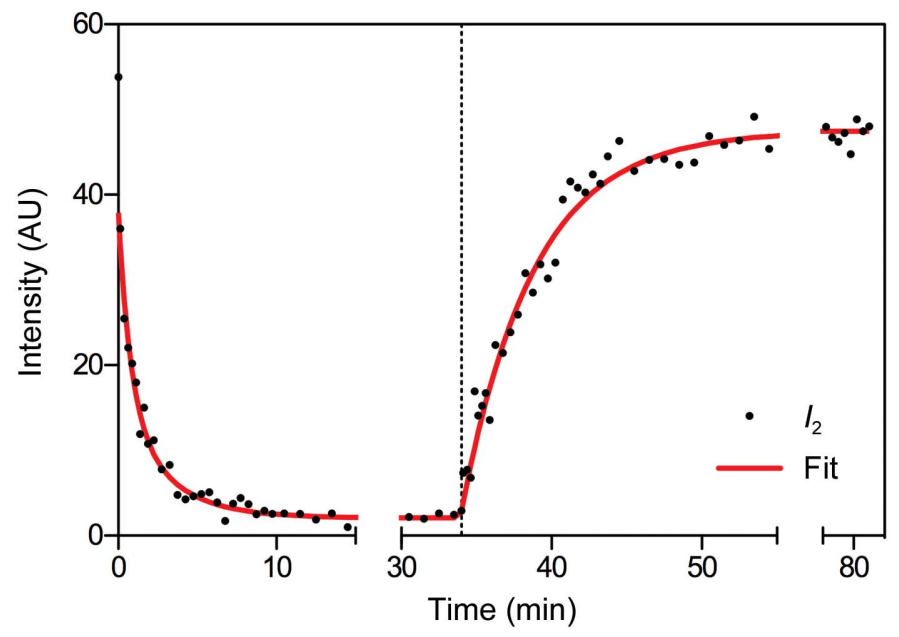

(b)

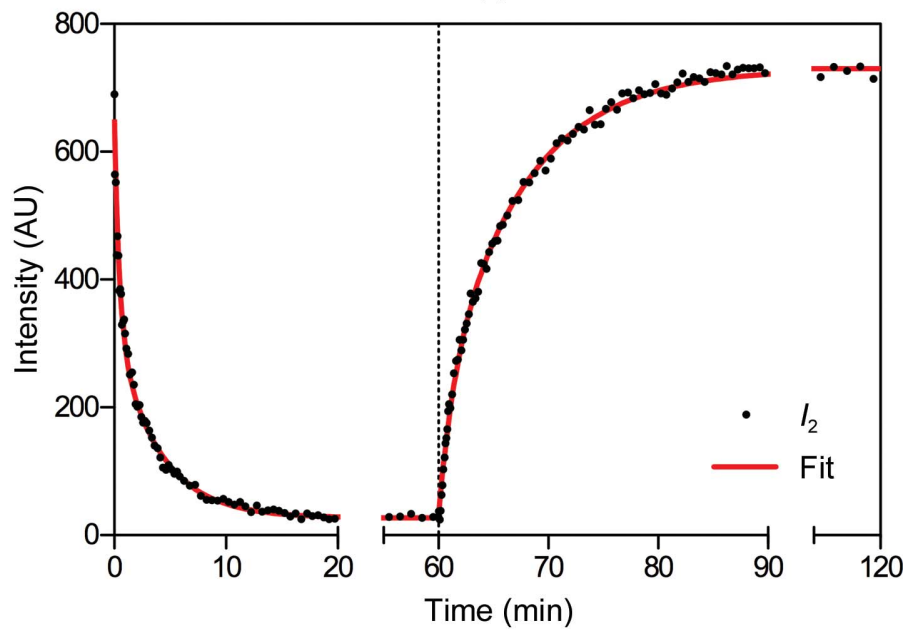

(d)

$\mathrm{H}_{2} \mathrm{O}-\mathrm{D}_{2} \mathrm{O}$ exchange kinetics in $(a)$ rat sciatic nerves, $(b)$ rat optic nerves, $(c)$ mouse sciatic nerves and $(d)$ mouse spinal cords. Samples equilibrated against $100 \% \mathrm{D}_{2} \mathrm{O}$-saline were first perfused with $20 \% \mathrm{D}_{2} \mathrm{O}$-saline $(t=0)$, followed by a perfusion with $100 \% \mathrm{D}_{2} \mathrm{O}$-saline (arrow) once equilibrium was reached. The extent of exchange is indicated by the change in intensity of the second-order reflection over time. Long periods with no change are indicated by breaks in the $x$ axis. Curves behind the data points represent double-exponential decay models fitted to the data. 
determined by measuring the change in intensity of the second-order Bragg reflection (which varies with the $\mathrm{D}_{2} \mathrm{O}$ content of myelin) over time (Fig. 6).

$\mathrm{H}_{2} \mathrm{O}-\mathrm{D}_{2} \mathrm{O}$ exchange in rat sciatic nerves from high to low $\% \mathrm{D}_{2} \mathrm{O}$-saline (typically $100 \rightarrow 20 \%$ ) occurred rapidly, and the decrease in $F_{2}$ followed a single exponential decay, with an average relaxation time $\left(\tau\right.$, or $\left.t_{1 / \mathrm{e}}\right)$ of $3.17 \pm 0.46 \mathrm{~min}(n=3$; Fig. $6 a$, Table 2). This was significantly shorter than previously measured in rabbit sciatic nerves, which had relaxation times of between 6 and 12 min (Kirschner et al., 1976). The longer times in the earlier study are likely to be accounted for by the $6^{\circ} \mathrm{C}$ temperature at which the nerves were maintained to preserve myelin integrity during long exposures. This temperature is only $2^{\circ} \mathrm{C}$ above the freezing point of pure $\mathrm{D}_{2} \mathrm{O}$ and results in a considerable increase in viscosity for both $\mathrm{D}_{2} \mathrm{O}$ and $\mathrm{H}_{2} \mathrm{O}$ (Hardy \& Cottington, 1949), lowering the diffusion rates. Our measurements were always performed at ambient temperature, where the viscosities of $\mathrm{D}_{2} \mathrm{O}$-saline and $\mathrm{H}_{2} \mathrm{O}$ saline are substantially lower and diffusion is more rapid. Additionally, the relatively large size and lower surface area to volume ratio of bundled rabbit sciatic nerves could provide additional barriers to the free diffusion of water. Therefore, our new measurements are likely to be a more accurate indication of the exchange kinetics of water in myelin. The reverse exchange $\left(20 \rightarrow 100 \% \quad \mathrm{D}_{2} \mathrm{O}\right.$-saline $)$ occurred more slowly than the forward exchange, with the relaxation times being $3.71 \pm 0.39 \mathrm{~min}(n=3$; Fig. $6 a$, Table 2$)$. This difference is consistent with previous measurements and is most likely to be caused by the $\sim 25 \%$ higher viscosity of $\mathrm{D}_{2} \mathrm{O}$ compared with that of $\mathrm{H}_{2} \mathrm{O}$ (Hardy \& Cottington, 1949).

$\mathrm{H}_{2} \mathrm{O}-\mathrm{D}_{2} \mathrm{O}$ exchange in rat optic nerves mostly followed a double exponential decay, in contrast to the single exponential decay observed in sciatic nerves. The decrease in $F_{2}$ for exchanges from high to low $\% \mathrm{D}_{2} \mathrm{O}$-saline proceeded with a primary relaxation time $\left(\tau_{1}\right)$ of $3.97 \pm 1.04 \min (n=5)$; for exchanges that showed a double exponential decay, an additional, very short relaxation time $\left(\tau_{2}\right)$ of $0.44 \pm 0.20 \mathrm{~min}(n=4)$ was required to best fit the data (Fig. 6b, Table 2). During the reverse exchange (from low to high $\% \mathrm{D}_{2} \mathrm{O}$-saline) the relaxation times were slightly longer, similar to the trend seen in the sciatic nerves. The reverse exchanges proceeded with a primary relaxation time of $4.75 \pm 1.43 \min (n=2)$; in one experiment, however, a secondary relaxation time of $0.67 \mathrm{~min}$ $(n=1)$ was required to fit the data (Fig. $6 b$, Table 2). The apparent inconsistencies in the exponential modelling of $\mathrm{H}_{2} \mathrm{O}-\mathrm{D}_{2} \mathrm{O}$ exchange in rat optic nerves can be explained by the relatively weak diffraction (Fig. 3) combined with the fact that many of the exchanges measured were performed between similar and often low levels of $\mathrm{D}_{2} \mathrm{O}$-saline (e.g. $60 \rightarrow 43 \%$ and $43 \rightarrow 20 \% \mathrm{D}_{2} \mathrm{O}$ ). Higher quality data from mouse spinal cord (below), however, validated our analysis here.

The water-exchange rates determined for mouse sciatic nerves were consistent with the data from rat sciatic nerves: exchange from 100 to $20 \% \mathrm{D}_{2} \mathrm{O}$-saline followed a single exponential decay with a relaxation time of $1.72 \mathrm{~min}(n=1)$, while the reverse exchange $\left(20 \rightarrow 100 \% \mathrm{D}_{2} \mathrm{O}\right.$-saline) showed a relaxation time of $2.47 \min (n=1$; Fig. $6 c$, Table 2). Exchange experiments were not performed on mouse optic nerves because of their weak diffracting power (Fig. 3). Instead, mouse spinal cords were examined. During exchange from 100 to $20 \% \mathrm{D}_{2} \mathrm{O}$-saline, these samples displayed a decrease in $F_{2}$ that consistently showed a double exponential decay, with a primary relaxation time of $5.84 \pm 1.15 \mathrm{~min}$ and a secondary relaxation time of $0.67 \pm 0.27 \mathrm{~min}(n=6$; Fig. $6 d$, Table 2). The reverse exchange $\left(20 \rightarrow 100 \% \mathrm{D}_{2} \mathrm{O}\right.$-saline $)$ was significantly slower, showing primary and secondary relaxation times of $7.48 \pm 1.11 \mathrm{~min}(p<0.05)$ and $0.71 \pm 0.03 \mathrm{~min}(n=6)$, respectively. Taken as a whole, the relaxation times were on average about $25 \%$ longer for exchanges from low to high $\% \mathrm{D}_{2} \mathrm{O}$ than from high to low $\% \mathrm{D}_{2} \mathrm{O}(n=6$; paired $t$-test; $p<0.04)$.

\subsection{The effect of heavy water on myelin structure}

It has previously been reported that frog (Rana pipiens) PNS myelin in $\mathrm{H}_{2} \mathrm{O}$-saline produces identical XRD patterns to nerves soaked in $\mathrm{D}_{2} \mathrm{O}$-saline (Akers \& Parsons, 1970). However, throughout our ND experiments, we noticed that the samples exhibited a slight, but constant, tendency towards a lower period as the concentration of $\mathrm{D}_{2} \mathrm{O}$ increased. This difference was typically no greater than $4 \AA$ between nerves in $100 \% \mathrm{H}_{2} \mathrm{O}$-saline versus nerves in $100 \% \mathrm{D}_{2} \mathrm{O}$-saline (data not shown). To test whether deuterium was causing unexpected structural changes, we soaked nerves in $\mathrm{H}_{2} \mathrm{O}$-saline and $\mathrm{D}_{2} \mathrm{O}$ saline and analyzed them using XRD, which does not distinguish between deuterium and hydrogen. We found that mouse sciatic nerves in $\mathrm{D}_{2} \mathrm{O}$-saline displayed a $1.6 \AA$ lower period in $\mathrm{D}_{2} \mathrm{O}$-saline, $173.3 \pm 0.1 \AA$, than in $\mathrm{H}_{2} \mathrm{O}$-saline, $174.9 \pm 0.1 \AA$ $(n=3$; paired $t$-test; $p<0.002$; Figs. $7 a$ and $7 c)$. Similarly, the myelin period in mouse spinal cord was $1.8 \AA$ lower in $\mathrm{D}_{2} \mathrm{O}$ saline, $156.6 \pm 0.3 \AA$, than in $\mathrm{H}_{2} \mathrm{O}$-saline, $158.3 \pm 0.4 \AA(n=3$, paired $t$-test, $p<0.02$; Figs. $7 b$ and $7 d$ ). Close examination and direct measurement of the relevant diffraction pattern in question (Akers \& Parsons, 1970) revealed an apparent $2 \AA$ expansion of frog PNS myelin in $\mathrm{D}_{2} \mathrm{O}$-saline that was unreported by the investigators. It is unclear whether the authors controlled for the difference in $\mathrm{p} K_{\mathrm{a}}$ between $\mathrm{H}_{2} \mathrm{O}$ and $\mathrm{D}_{2} \mathrm{O}$. If not, the increased alkalinity of $\mathrm{D}_{2} \mathrm{O}$-saline (by 0.4 units) could account for the observed increase in period (Akers \& Parsons, 1970); similarly, a slight increase in ionic strength owing to the additional acid used to equalize the $\mathrm{pH} / \mathrm{pD}$ of $\mathrm{H}_{2} \mathrm{O}$ and $\mathrm{D}_{2} \mathrm{O}$ containing buffers may account for the compaction observed in the present study (Inouye \& Kirschner, 1988; Worthington \& Blaurock, 1969; Finean \& Millington, 1957; Worthington, 1979; Robertson, 1958). Although these changes only represent a $\sim 1 \%$ reduction in period, these results emphasize the dynamic nature of myelin and demonstrate the ability of diffraction-based methods to detect subtle changes in structure.

\section{Discussion}

Early EM studies of myelin revealed a significant amount of structural complexity (Schnapp \& Mugnaini, 1975), and 
with the development of advanced imaging techniques and molecular-biology in the last few decades, researchers have been able to identify and localize the molecular constituents of myelin (Trapp \& Kidd, 2004; Arroyo \& Scherer, 2000; Scherer \& Arroyo, 2002). Examining the molecular organization, structural dynamics and structure-function relationships in myelin, however, remains challenging because of the nanometre scale of the structural features of myelin. Of the methods that have sufficient resolving power, EM is the most prevalent; unfortunately, owing to processing artifacts, elec- tron micrographs are rarely faithful representations of the native state of the tissue. For example, EM may give a false impression that myelin is a static structure by virtue of the uniformly static images that it produces. Additionally, the chemical and physical treatments that are routinely, and necessarily, applied to myelin prior to EM analysis can obscure or alter the structural features of myelin (Moretz et al., 1969a,b; Kirschner \& Hollingshead, 1980; Avila et al., 2005). A compelling illustration of this is the once-held belief that myelin was entirely devoid of transmembrane proteins, as

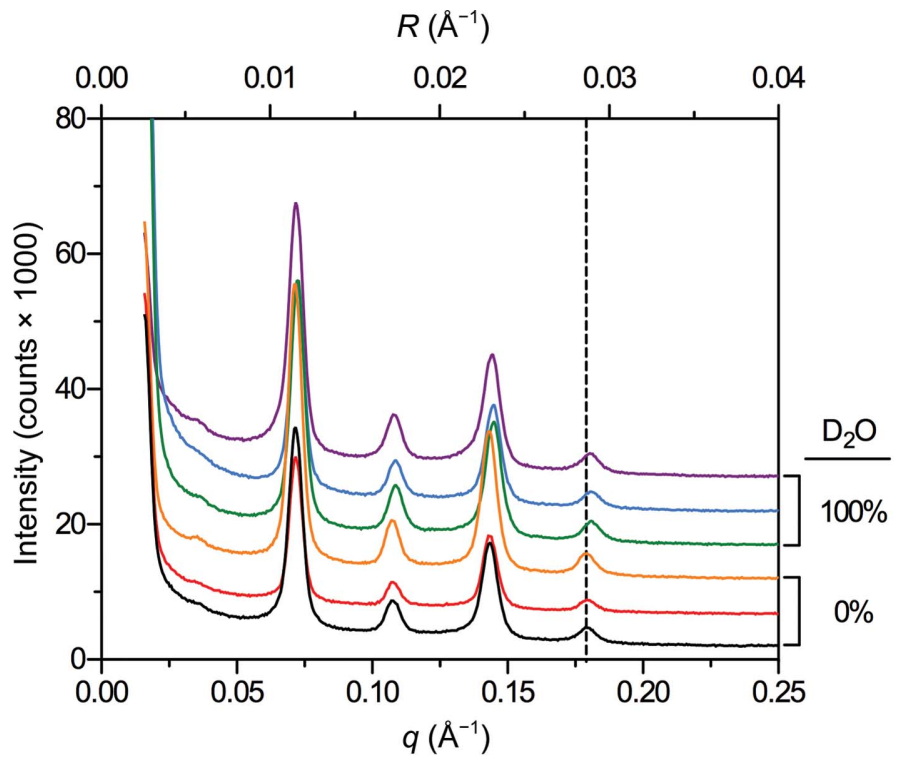

(a)

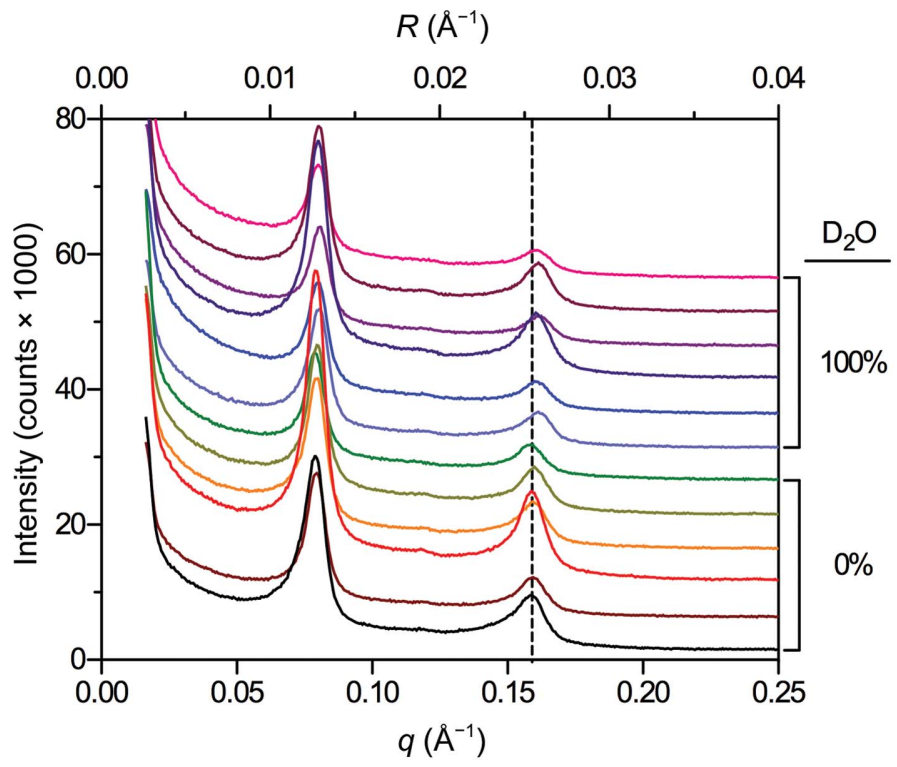

(c)

Figure 7

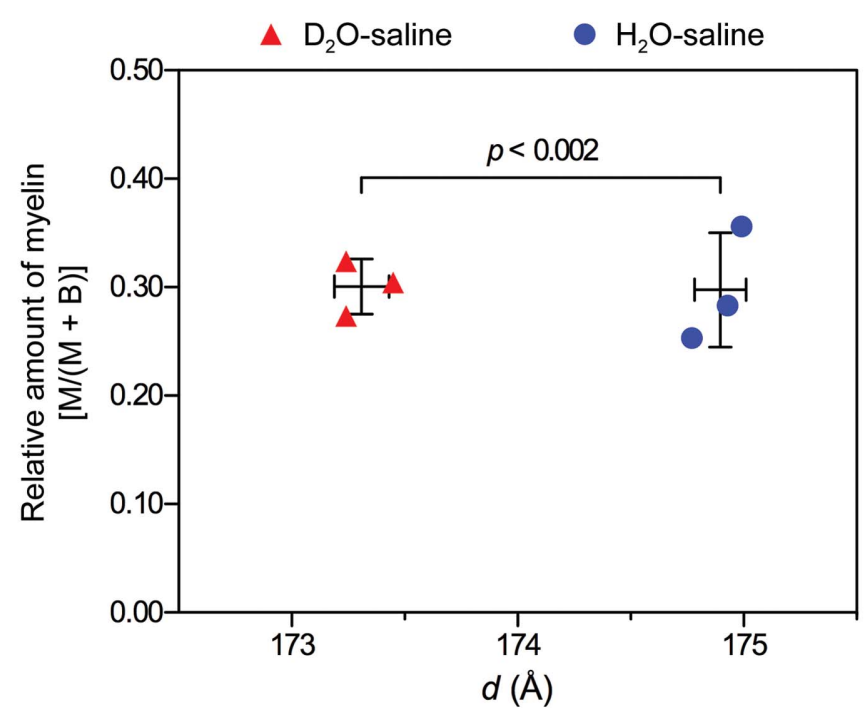

(b)

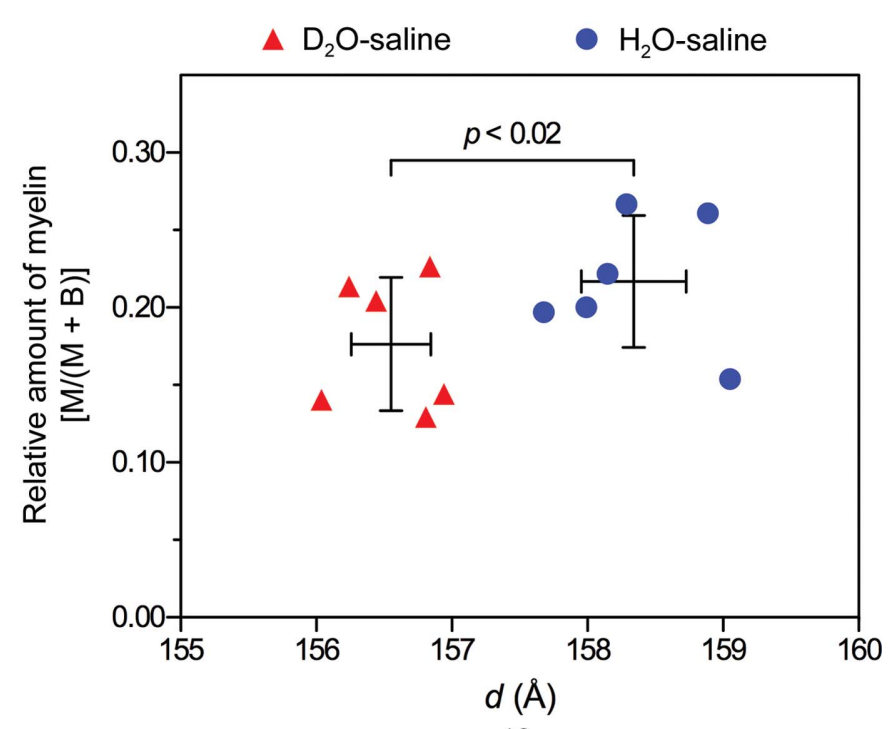

$(d)$

Subtle effect of heavy water on the myelin period. $(a, c)$ X-ray diffraction patterns collected from mouse $(a)$ sciatic nerves and $(c)$ spinal cord segments equilibrated against either $\mathrm{H}_{2} \mathrm{O}$-saline or $\mathrm{D}_{2} \mathrm{O}$-saline. Scattering intensity is plotted against both the scattering vector $q\left(\AA^{-1}\right)$ and the reciprocal coordinate $R\left(\AA^{-1}\right)$. For clarity, the spectra have been offset along the $y$ axis. For comparison, the dashed lines represent the average positions of the fifth-order and fourth-order reflection from sciatic nerves and spinal cords, respectively, in $\mathrm{H}_{2} \mathrm{O}$-saline. $(b, d)$ Scatter plots of relative amount of myelin $[\mathrm{M} /(\mathrm{M}+\mathrm{B})]$ versus myelin period $d$ for mouse sciatic nerves $(b)$ and spinal cords $(d)$ equilibrated against either $\mathrm{H}_{2} \mathrm{O}$-saline or $\mathrm{D}_{2} \mathrm{O}$-saline. Error bars represent \pm 1 standard deviation centred on the average for each group. Statistical significance was calculated using a paired $t$-test on parameters measured from single sciatic nerves or averaged parameters from two segments of spinal cord isolated from each mouse $(n=3)$ split between each of the two treatments. 
shown by the smooth membrane surfaces observed in freezefracture EM (Branton, 1967); this was later discovered to be the artifactual result of insufficient equilibration of cryoprotectants in the multilamellar structure (Kirschner et al., 1979; Hollingshead et al., 1981). Other misconceptions, however, persist. Among them is the pervasive usage of the term 'major dense line' to refer to the cytoplasmic apposition of myelin. Although commonplace, this term derives from the highly compacted and dense appearance of this space in electron micrographs, which is caused by osmication and dehydration during conventional tissue processing (Kirschner \& Hollingshead, 1980). In untreated tissue, the cytoplasmic and extracellular spaces of CNS myelin are similar in size and electron density. These, and other treatments involved in tissue processing, are also responsible for the $\sim 20-30 \%$ reduction in the myelin period typically measured from electron micrographs compared with that determined by XRD experiments on fresh tissue. Issues pertaining to accurate determinations and depictions of myelin structure are important, as the size and accessibility of the cytoplasmic space are implicated in myelin biogenesis and the maintenance of myelin organization (Aggarwal et al., 2011, 2013; Snaidero et al., 2014). Recent advances in high-pressure freezing and freeze-substitution have improved tissue preservation with respect to antigen preservation (Kirschning et al., 1998); however, even these methods eventually rely on chemical fixation and fail to maintain important features of the myelin structure (i.e. the myelin period and intermembrane packing distances; Möbius et al., 2008, 2010).

To understand myelin biogenesis, architecture and dynamics, an accurate view of the myelin structure is essential for interpreting recent developments and informing future work. For these reasons, diffraction-based methods are often a necessary complement to the microscopic analysis of myelin; in diffraction experiments, samples can be analyzed fresh and immediately after dissection, completely avoiding the artifacts introduced by tissue processing. Diffraction methods largely depend on the presence of periodic structure within the sample; therefore, the repetitive nature of myelin membrane packing and other nervous-system assemblies (e.g. the radial component, paranodal loops, paranodal junctions, neurofilaments, microtubules and collagen) make the nervous system a highly amenable target for diffraction. The challenge lies in tailoring the experimental setup (i.e. radiation type; beam characteristics; detector efficiency, resolution and placement; and sample preparation and orientation) to highlight the features of interest. For example, the recent use of a $1 \mu \mathrm{m}$ diameter X-ray microbeam to study membrane packing in internodal, juxtaparanodal and paranodal myelin in single myelinated nerves as well as the in-plane aggregation of P0 glycoprotein in situ aptly demonstrates the power of diffraction-based methods (Inouye et al., 2014).

Here, we explored the use of ND as a potential method for myelin structural analysis. Compared with the more common $\mathrm{XRD}$, which measures periodic fluctuations in electron density, ND measures variations in nuclear structure (neutron scattering density) within the sample and is especially sensitive to the presence of deuterium, a heavy isotope of hydrogen (Bacon \& Lonsdale, 1953). Thus, if a defined population of $\mathrm{H}$ atoms within a biological sample can be replaced (either partially or completely) with deuterium, the position of this substitution can be determined with high accuracy (Büldt et al., 1978, 1979; Zaccai et al., 1975, 1979; Worcester \& Franks, 1976). In our experiments, we performed a bulk exchange in rodent nervous tissue with buffers containing mixtures of light water $\left(\mathrm{H}_{2} \mathrm{O}\right)$ and heavy water $\left(\mathrm{D}_{2} \mathrm{O}\right)$ and analyzed the samples using ND. Through this simple replacement, we were able to localize readily exchangeable $\mathrm{H}$ atoms (from both bulk water and ionizable chemical groups), determine myelin structural parameters and measure $\mathrm{H}-\mathrm{D}$ exchange kinetics in $\mathrm{CNS}$ and PNS myelin.

Our ND experiments on sciatic nerve myelin revealed structural details that were not seen in previous experiments from $\sim 45$ years ago (Parsons \& Akers, 1969). Originally, only a single second-order reflection was observed from both rabbit and human peripheral nerves in $100 \% \mathrm{D}_{2} \mathrm{O}$-saline, suggesting a simple, cosinusoidal distribution of neutron scattering density in myelin that corresponded to the alternating extracellular and cytoplasmic layers of exchangeable water (Parsons \& Akers, 1969); however, this model lacked any fine structural detail. Subsequent work using rabbit sciatic nerve in $100 \% \mathrm{D}_{2} \mathrm{O}$-saline revealed additional Bragg orders (1-4, 6 and 7), which contributed to a more detailed neutron scattering density profile (Kirschner et al., 1976). In our current ND experiments, which used the considerably smaller sciatic nerves from rat and mouse, we typically observed Bragg orders $1-7$, and also recorded orders $1-6$ and 8 from rat sciatic nerves in $100 \% \mathrm{H}_{2} \mathrm{O}$-saline, despite the strong incoherent neutron scattering signal from $\mathrm{H}_{2} \mathrm{O}$. A previous ND study using human sciatic nerves in $\mathrm{H}_{2} \mathrm{O}$ was unable to detect any coherent neutron scatter from the sample (Parsons \& Akers, 1969). Additionally, we analyzed CNS myelin (rat optic nerves and mouse spinal cord) and recorded Bragg orders 1, 2, 4 and 6 in $\mathrm{D}_{2} \mathrm{O}$ and orders 1 and 4 in $\mathrm{H}_{2} \mathrm{O}$; previously, only a single second-order reflection had been observed from samples in $\mathrm{D}_{2} \mathrm{O}$ (Worcester, 1976). Notably, all analyses were performed on samples from single animals, minimizing the influence of inter-animal variation for each measurement. Furthermore, the exposure times in our static experiments were $1-5 \mathrm{~h}$, significantly shorter than the $8 \mathrm{~h}$ to $4 \mathrm{~d}$ exposures previously used (Kirschner et al., 1976).

Neutron scattering density profiles from rodent CNS and PNS myelin demonstrated the familiar double-membrane bilayer organization of the myelin sheath in the internode. At low $\% \mathrm{D}_{2} \mathrm{O}$, the membrane-bilayer hydrocarbon core, polar headgroup peaks and aqueous compartments were clearly delineated. For all samples, the distance across the bilayer was 40-46 $\AA$, while the cytoplasmic compartment was measured to be $32-37 \AA$; the width of the extracellular space varied between CNS (32-40 $)$ ) and PNS (47-55 $⿱$ ) myelin. These dimensions are consistent with numerous XRD experiments on myelin (reviewed in Kirschner \& Blaurock, 1992). At high $\% \mathrm{D}_{2} \mathrm{O}$, the similarity in water content of the two aqueous compartments of myelin was apparent. This is in stark contrast 
to the condensed nature of the major dense line as observed in EM. It is commonly written that the major dense line is formed by the fusion of cytoplasmic leaflets of the oligodendrocyte/Schwann-cell membrane and is therefore devoid of cytoplasm; however, our measurements clearly demonstrate that the cytoplasmic apposition is similar to the extracellular apposition in terms of width (CNS) and water content (CNS and PNS), and could harbour small metabolites and other molecules in an aqueous environment.

Our analysis of the ND data also revealed more subtle variations in membrane structure. In particular, we measured an apparent asymmetry in the bilayer, as shown by an increased neutron scattering density in the extracellular leaflet. The higher scattering density of the extracellular leaflet may represent an enrichment of cholesterol on this side of the membrane, as the steroid nucleus of cholesterol has a higher neutron scattering density than stiff-chain hydrocarbon: 0.07 $\times 10^{11}$ versus $-0.01 \times 10^{11} \mathrm{~cm}^{-2}$, respectively (Kirschner, 1974). The asymmetric distribution of cholesterol in myelin was suggested previously by high-resolution X-ray diffraction studies (Caspar \& Kirschner, 1971).

In addition to static measurements performed on freshly dissected samples in sealed capillaries, we also used ND to measure $\mathrm{H}_{2} \mathrm{O}-\mathrm{D}_{2} \mathrm{O}$ exchange kinetics in samples that were continuously perfused with fluid. These experiments required the collection of a series of short, consecutive exposures. $\mathrm{H}_{2} \mathrm{O}-$ $\mathrm{D}_{2} \mathrm{O}$ exchange was monitored using exposure times less than one-tenth as long as previously used for samples that were as much as tenfold greater in size, demonstrating the improved capabilities of current neutron technology. Analysis of $\mathrm{H}_{2} \mathrm{O}-$ $\mathrm{D}_{2} \mathrm{O}$ exchange revealed consistent differences between CNS and PNS myelin. On average, exchange in PNS tissue was almost twice as rapid as that in CNS tissue $\left(\tau_{1} ; n=4 ; p<0.03\right)$. Furthermore, exchange generally proceeded with a single exponential decay in PNS myelin, whereas in CNS myelin double-exponential fits were required to model the exchange data. This difference between CNS and PNS myelin indicates the existence of two somewhat distinct populations of exchangeable $\mathrm{H}$ atoms within myelin: the rapidly exchanging bulk water and the more slowly exchanging interfacial water and labile $\mathrm{H}$ atoms bound to macromolecules, or populations of water/hydrogen in either the cytoplasmic or extracellular compartments. Identification of these populations may reveal important insights into the water and solute permeability of internodal myelin.

The current study demonstrates the renewed potential for ND studies on myelin and other natural biological membranes. Although the simple ex vivo exchange of water performed here provides valuable insight into the distribution and accessibility of water within myelin, alternative routes of administration and/or the use of other deuterated molecules will facilitate the tackling of additional questions. For example, simple ex vivo treatment of myelin could address the interactions of biologically relevant deuterated small molecules with myelin (e.g. anesthetics, organic solvents or fixatives such as glutaraldehyde). More elaborate studies could involve the in vivo incorporation of deuterium into the membranes during myelination. Because mice can tolerate $>30 \% \mathrm{D}_{2} \mathrm{O}$ in their drinking water indefinitely, one can expect $>15 \%$ replacement of hydrogen by deuterium in newly synthesized lipids and proteins (Katz et al., 1962; Ando et al., 2003) through a simple feeding protocol. This broad labelling technique should impart sufficient contrast to highlight the hydrogen-rich hydrocarbon core of the bilayer and to allow its dimensions and internal distribution of hydrogen to be examined. A similar approach could be taken to analyze the distribution of single lipid species within the membrane. For example, the proposed asymmetric distribution of cholesterol could be addressed through the administration of deuterated cholesterol to pregnant dams and then postnatally, enabling the labelled cholesterol to become incorporated into tissues during the early development and maturation of the pups (Woollett, 1996; Scott et al., 1980; Wechsler et al., 2003). Similarly, the use of deuterated lipid precursors (e.g. ketone bodies, mevalonate and fatty acids) or targeted delivery techniques may allow the appropriation of endogenous synthesis pathways and confinement of the label to a tissue of interest (Chevallier \& Gautheron, 1969; Edmond, 1974; Sun \& Horrocks, 1973; Gozlan-Devillierre et al., 1978).

Beyond elucidating the structure of myelin, neutron diffraction holds much promise in analyzing the function of myelin. The monitoring over time of a simple exchange of deuterated and protonated material provides a direct and focused measure of internodal myelin function and integrity, in contrast to the bulk electrophysiological properties of myelinated tissue that is often used to interrogate myelin function. The uncoupling of myelin function and nerve conduction allows myelin to be studied in relative isolation, which could be exploited to measure the permeability of not only healthy myelin but also myelin from transgenic animals and animal models of human myelinopathies. For example, mice lacking components of the axo-glial junctions or interlamellar tight junctions and animal models of multiple sclerosis, such as the experimental autoimmune encephalomyelitis (EAE) mouse, would be of particular interest. A forthcoming manuscript will focus on our use of ND and XRD to characterize myelin from mice lacking the CNS interlamellar tight junction protein claudin-11 (Gow et al., 1999; Devaux \& Gow, 2008).

We thank Adrian Perkins and Didier Richard at the ILL and Dominique Dallery, Charlene Caloud and Helene Bernard at the ESRF for experimental support. We thank Dr Alexander Gow and Kathleen Maheras (Wayne State University Medical School, Detroit, Michigan, USA) for providing some of the animals used in this study. We thank Brian White and Perry Nuckle at NOVA Scientific Inc. (Sturbridge, Massachusetts, USA) for designing and fabricating the perfusion cell used at the ILL. We thank Paul Dee at Boston College for fabricating additional perfusion cells. We are indebted to Dr G. Zaccai for his continuing interest and enthusiastic encouragement of this research. This research was supported by the Fondation pour l'Aide à la Recherche sur la Sclérose en Plaques (ARSEP Foundation), 
L'Association Européenne contre les Leucodystrophies ELA (ELA Foundation, grant Nos. ELA2008-009C4 and ELA2010-042C5), Boston College Institutional Research Funds (DAK), the Burroughs Wellcome Fund (Collaborative Research Travel Grant; ARD) and the NIH (SBIR Phase I grant R43GM 103664-01; WBF).

\section{References}

Aggarwal, S., Snaidero, N., Pähler, G., Frey, S., Sánchez, P., Zweckstetter, M., Janshoff, A., Schneider, A., Weil, M. T., Schaap, I. A., Görlich, D., Simons, M. \& Barres, B. A. (2013). PLoS Biol. 11, e1001577.

Aggarwal, S., Yurlova, L., Snaidero, N., Reetz, C., Frey, S., Zimmermann, J., Pähler, G., Janshoff, A., Friedrichs, J., Müller, D. J., Goebel, C. \& Simons, M. (2011). Dev. Cell, 21, 445-456.

Akers, C. K. \& Parsons, D. F. (1970). Biochim. Biophys. Acta, 211, 95-97.

Ando, S., Tanaka, Y., Toyoda, Y. \& Kon, K. (2003). Neurochem. Res. 28, 5-13.

Arroyo, E. J. \& Scherer, S. S. (2000). Histochemistry, 113, 1-18.

Avila, R. L., Inouye, H., Baek, R. C., Yin, X., Trapp, B. D., Feltri, M. L., Wrabetz, L. \& Kirschner, D. A. (2005). J. Neuropathol. Exp. Neurol. 64, 976-990.

Bacon, G. E. \& Lonsdale, K. (1953). Rep. Prog. Phys. 16, 1-61.

Branton, D. (1967). Exp. Cell Res. 45, 703-707.

Büldt, G., Gally, H. U., Seelig, A., Seelig, J. \& Zaccai, G. (1978). Nature (London), 271, 182-184.

Büldt, G., Gally, H. U., Seelig, J. \& Zaccai, G. (1979). J. Mol. Biol. 134, 673-691.

Caspar, D. L. \& Kirschner, D. A. (1971). Nature New Biol. 231, 46-52.

Caspar, D. L. \& Phillips, W. C. (1976). Brookhaven Symp. Biol. 27, VII107-VII125.

Chevallier, F. \& Gautheron, C. (1969). J. Neurochem. 16, 323-331.

DeBruin, L. S. \& Harauz, G. (2007). Neurochem. Res. 32, 213-228.

Devaux, J. \& Gow, A. (2008). J. Cell Biol. 183, 909-921.

Edmond, J. (1974). J. Biol. Chem. 249, 72-80.

Finean, J. B. \& Millington, P. F. (1957). J. Biophys. Biochem. Cytol. 3, 89-94.

Franks, N. P., Arunachalam, T. \& Caspi, E. (1978). Nature (London), 276, 530-532.

Franks, N. P. \& Lieb, W. R. (1979). J. Mol. Biol. 133, 469-500.

Gow, A., Southwood, C. M., Li, J. S., Pariali, M., Riordan, G. P., Brodie, S. E., Danias, J., Bronstein, J. M., Kachar, B. \& Lazzarini, R. A. (1999). Cell, 99, 649-659.

Gozlan-Devillierre, N., Baumann, N. \& Bourre, J.-M. (1978). Biochim. Biophys. Acta, 528, 490-496.

Hardy, R. C. \& Cottington, R. L. (1949). J. Chem. Phys. 17, 509-510.

Haywood, B. C. \& Worcester, D. L. (1973). J. Phys. E, 6, 568-571.

He, K., Ludtke, S. J., Wu, Y. \& Huang, H. W. (1993). Biophys. J. 64, 157-162.

Hollingshead, C. J., Caspar, D. L., Melchior, V. \& Kirschner, D. A. (1981). J. Cell Biol. 89, 631-644.

Hristova, K. \& White, S. H. (1998). Biophys. J. 74, 2419-2433.

Inouye, H., Karthigasan, J. \& Kirschner, D. A. (1989). Biophys. J. 56, 129-137.

Inouye, H. \& Kirschner, D. A. (1988). Biophys. J. 53, 235-245.

Inouye, H., Liu, J., Makowski, L., Palmisano, M., Burghammer, M., Riekel, C., Kirschner, D. A. \& Gasset, M. (2014). PLoS One, 9, e100592.

Katsaras, J. \& Stinson, R. H. (1990). Biophys. J. 57, 649-655.
Katz, J. J., Crespi, H. L., Czajka, D. M. \& Finkel, A. J. (1962). Am. J. Physiol. 203, 907-913.

Kirschner, D. A. (1974). Comparative X-ray and Neutron Diffraction from Nerve Myelin Membranes, edited by S. Yip \& S.-H. Chen, pp. 203-233. New York: Academic Press.

Kirschner, D. A. \& Blaurock, A. E. (1992). Organization, Phylogenetic Variations and Dynamic Transitions of Myelin Structure, edited by R. E. Martenson, pp. 3-78. Boca Raton: CRC Press.

Kirschner, D. A. \& Caspar, D. L. (1975). Proc. Natl Acad. Sci. USA, 72, 3513-3517.

Kirschner, D. A., Caspar, D. L., Schoenborn, B. P. \& Nunes, A. C. (1976). Brookhaven Symp. Biol. 27, III68-III76.

Kirschner, D. A. \& Hollingshead, C. J. (1980). J. Ultrastruct. Res. 73, 211-232.

Kirschner, D. A., Hollingshead, C. J., Thaxton, C., Caspar, D. L. \& Goodenough, D. A. (1979). J. Cell Biol. 82, 140-149.

Kirschning, E., Rutter, G. \& Hohenberg, H. (1998). J. Neurosci. Res. 53, 465-474.

Lytz, R. K., Reinert, J. C., Church, S. E. \& Wickman, H. H. (1984). Chem. Phys. Lipids, 35, 63-76.

MacNaughtan, W., Snook, K. A., Caspi, E. \& Franks, N. P. (1985). Biochim. Biophys. Acta, 818, 132-148.

McIntosh, T. J. \& Holloway, P. W. (1987). Biochemistry, 26, $1783-$ 1788.

Möbius, W., Cooper, B., Kaufmann, W. A., Imig, C., Ruhwedel, T., Snaidero, N., Saab, A. S. \& Varoqueaux, F. (2010). Methods Cell Biol. 96, 475-512.

Möbius, W., Patzig, J., Nave, K. A. \& Werner, H. B. (2008). Neuron Glia Biol. 4, 111-127.

Moretz, R. C., Akers, C. K. \& Parsons, D. F. (1969a). Biochim. Biophys. Acta, 193, 1-11.

Moretz, R. C., Akers, C. K. \& Parsons, D. F. (1969b). Biochim. Biophys. Acta, 193, 12-21.

Parsons, D. F. \& Akers, C. K. (1969). Science, 165, 1016-1018.

Robertson, J. D. (1958). J. Cell Biol. 4, 349-364.

Scherer, S. S. \& Arroyo, E. J. (2002). J. Peripher. Nerv. Syst. 7, 1-12.

Schnapp, B. \& Mugnaini, E. (1975). The Myelin Sheath: Electron Microscopic Studies with Thin Sections and Freeze-Fracture, edited by M. Santini, pp. 209-233. New York: Raven Press.

Scott, S. C., Bruckdorfer, K. R. \& Worcester, D. L. (1980). Biochem. Soc. Trans. 8, 717.

Snaidero, N., Möbius, W., Czopka, T., Hekking, L. H., Mathisen, C., Verkleij, D., Goebbels, S., Edgar, J., Merkler, D., Lyons, D. A., Nave, K. A. \& Simons, M. (2014). Cell, 156, 277-290.

Sun, G. Y. \& Horrocks, L. A. (1973). J. Lipid Res. 14, 206-214.

Trapp, B. D. \& Kidd, G. J. (2004). Structure of the Myelinated Axon, edited by R. Lazzarini, pp. 3-25. New York: Elsevier.

Wechsler, A. et al. (2003). Science, 302, 2087.

White, S. H. \& Wiener, M. C. (1995). Determination of the Structure of Fluid Lipid Bilayer Membranes, edited by E. A. Disalvo \& S. A. Simon, pp. 1-19. Boca Raton: CRC Press.

Wiener, M. C. \& White, S. H. (1991). Biochemistry, 30, 6997-7008.

Woollett, L. A. (1996). J. Lipid Res. 37, 1246-1257.

Worcester, D. (1976). Biological Membranes, Vol. 3, edited by D. J. Chapman \& D. F. H. Wallach, pp. 1-46. New York: Academic Press.

Worcester, D. L. \& Franks, N. P. (1976). J. Mol. Biol. 100, 359-378.

Worthington, C. R. (1979). Int. J. Biol. Macromol. 1, 157-164.

Worthington, C. R. \& Blaurock, A. E. (1969). Biochim. Biophys. Acta, 173, 427-435.

Zaccai, G., Blasie, J. K. \& Schoenborn, B. P. (1975). Proc. Natl Acad. Sci. USA, 72, 376-380.

Zaccai, G., Büldt, G., Seelig, A. \& Seelig, J. (1979). J. Mol. Biol. 134, 693-706. 